\title{
Improving anti-cancer drug delivery performance of magnetic mesoporous silica nanocarriers for more efficient colorectal cancer therapy
}

Sonia Iranpour ${ }^{1}$, Ahmad Reza Bahrami ${ }^{1,2}$, Sirous Nekooei ${ }^{3}$, Amir Sh. Saljooghi ${ }^{4,5^{*}}$ and Maryam M. Matin ${ }^{1,5^{*}(\text { ) }}$

\begin{abstract}
Background: Improving anti-cancer drug delivery performance can be achieved through designing smart and targeted drug delivery systems (DDSs). For this aim, it is important to evaluate overexpressed biomarkers in the tumor microenvironment (TME) for optimizing DDSs.

Materials and methods: Herein, we designed a novel DDS based on magnetic mesoporous silica core-shell nanoparticles (SPION@MSNs) in which release of doxorubicin (DOX) at the physiologic pH was blocked with gold gatekeepers. In this platform, we conjugated heterofunctional polyethylene glycol (PEG) onto the outer surface of nanocarriers to increase their biocompatibility. At the final stage, an epithelial cell adhesion molecule (EpCAM) aptamer as an active targeting moiety was covalently attached (Apt-PEG-Au@NPs-DOX) for selective drug delivery to colorectal cancer (CRC) cells. The physicochemical properties of non-targeted and targeted nanocarriers were fully characterized. The anti-cancer activity, cellular internalization, and then the cell death mechanism of prepared nanocarriers were determined and compared in vitro. Finally, tumor inhibitory effects, biodistribution and possible side effects of the nanocarriers were evaluated in immunocompromised C57BL/6 mice bearing human HT-29 tumors.

Results: Nanocarriers were successfully synthesized with a mean final size diameter of $58.22 \pm 8.54 \mathrm{~nm}$. Higher cytotoxicity and cellular uptake of targeted nanocarriers were shown in the EpCAM-positive HT-29 cells as compared to the EpCAM-negative $\mathrm{CHO}$ cells, indicating the efficacy of aptamer as a targeting agent. In vivo results in a humanized mouse model showed that targeted nanocarriers could effectively increase DOX accumulation in the tumor site, inhibit tumor growth, and reduce the adverse side effects.
\end{abstract}

Conclusion: These results suggest that corporation of a magnetic core, gold gatekeeper, PEG and aptamer can strongly improve drug delivery performance and provide a theranostic DDS for efficient CRC therapy.

Keywords: Colorectal cancer, Drug delivery system, pH-sensitive gatekeeper, Targeted therapy, Theranostic, Magnetic mesoporous silica NPs

\footnotetext{
*Correspondence: saljooghi@um.ac.ir; matin@um.ac.ir

${ }^{1}$ Department of Biology, Faculty of Science, Ferdowsi University of Mashhad, Mashhad, Iran

${ }^{4}$ Department of Chemistry, Faculty of Science, Ferdowsi University of Mashhad, Mashhad, Iran

Full list of author information is available at the end of the article
}

\section{Background}

Cancer is one of the most devastating problems in the world, and colorectal cancer (CRC) has been reported as the second leading cause of cancer related death in both sexes as evident from the GLOBOCAN database [1]. In this regard, researchers are constantly searching for novel permits use, sharing, adaptation, distribution and reproduction in any medium or format, as long as you give appropriate credit to the original author(s) and the source, provide a link to the Creative Commons licence, and indicate if changes were made. The images or other third party material in this article are included in the article's Creative Commons licence, unless indicated otherwise in a credit line to the material. If material is not included in the article's Creative Commons licence and your intended use is not permitted by statutory regulation or exceeds the permitted use, you will need to obtain permission directly from the copyright holder. To view a copy of this licence, visit http://creativecommons.org/licenses/by/4.0/. The Creative Commons Public Domain Dedication waiver (http://creativeco mmons.org/publicdomain/zero/1.0/) applies to the data made available in this article, unless otherwise stated in a credit line to the data. 
and more effective treatment strategies to improve therapeutic outcomes with focus on patients' convenience. Nanotechnology has had a great impact on cancer treatment field by introducing various types of theranostic nano-delivery platforms [2]. Incorporation of traceable imaging modalities and therapeutic compounds on a single nano-delivery system provides a theranostic platform which results in efficient targeted therapy through imageguided drug delivery [3]. Generally, in order to improve drawbacks of conventional anti-cancer drugs and maximize drug delivery performance, it is necessary to consider two crucial aspects including (1) physicochemical parameters of nanoparticles (NPs) and (2) tumor microenvironment (TME) features.

Mesoporous silica nanoparticles (MSNs) constitute one of the most important classes of inorganic nanomaterials which can be used as an effective drug delivery system (DDS)/or nanocarrier [4]. MSN has received much attention due to its unique properties including porosity [5], dual/or multiple drug loading capacity [6, 7], biodegradable characteristics [8], biocompatible features [9], controlled drug release and incorporation with detectable agents [10, 11]. Intelligent drug release from MSNs at the intended site can be managed by conjugation of specific gatekeepers at pore entrances which can be controlled by endogenous and/or exogenous stimuli [12]. Generally, the $\mathrm{pH}$ value of TME is slightly lower than normal tissues [13]; therefor functionalized MSNs with $\mathrm{pH}$-responsive gatekeepers such as gold NPs can effectively turn closed tunnels to an open state, in response to an endogenous stimulus, and regulate the release of guest molecules [14]. In this context, several smart pH-responsive MSNs based on gold NPs have been developed for an on-demand release of anti-cancer drugs $[15,16]$. Moreover, some critical challenges such as half-life of nanocarriers in the blood, their toxicity, hemolysis of erythrocytes, and recognition of DDSs by host immune cells need to be addressed prior to the design, synthesis, and widespread employment of DDSs. It has been proven that PEGylation method is a mainstay strategy to overcome some of the mentioned problems $[17,18]$. Polyethylene glycol (PEG), an FDA-approved polymer for different drugs [19], can effectively cover the MSN surface and make it favorable for systemic administration, resulting in improved pharmacological properties of nanocarriers and optimizing the drug delivery behavior [20].

Generally, nanocarriers can passively reach the tumor site through enhanced permeability and retention (EPR) effect [21], and specific recognition of cancer cells in the TME is an important step to exert their destructive effects. Therefore, screening and identification of particular overexpressed cancer cell receptors in the TME is an effective way for selective delivery of therapeutic drugs.
This approach is called targeted drug delivery and specific moieties such as various aptamers have been designed and conjugated on the surface of DDSs to improve identifying their cognate receptors on cancer cells. Targeted drug delivery strategy maximizes availability of anticancer drugs at the tumor site, significantly minimizes adverse side effects, and ultimately helps to improve clinical outcomes [22, 23]. Epithelial cell adhesion molecule (EpCAM; CD326) is a cell surface receptor which is abundantly overexpressed in the rectal cancer tissue as compared with adjacent normal tissues [24], so it can be considered as an ideal CRC biomarker in active targeting. In this regard, Xie et al. increased the therapeutic efficacy of DOX against SW620 colon cancer cells by modification of MSNs with a DNA EpCAM aptamer and showed considerably increased toxicity of DOX in comparison with non-targeted MSNs [25]. Another group designed multifunctional MSNs with focusing on intelligent drug release, high circulatory half-life, and selective delivery of a maytansine derivative (DM1) for CRC treatment. For this aim, hydrochloride polydopamine (PDA) as a wellknown gatekeeper, PEG and DNA EpCAM aptamer were applied and created a favorable platform for CRC therapy. Both in vitro and in vivo results confirmed advantages of prepared MSNs in specific targeting of cancer cells with low off-target toxicity [26]. Moreover, Gao et al. applied two aptamers on the surface of MSNs in order to improve specific recognition of colon cancer cells, overcome the heterogeneity patterns and prevent lung metastasis. They showed modification of MSNs with both EpCAM and CD44 aptamers could coordinately restrain proliferation and metastasis of SW620 colon cancer cells [27].

Herein, we improved anti-cancer drug delivery performance by designing smart and targeted magnetic mesoporous silica core-shell NPs as a theranostic nanodelivery platform for CRC therapy. For this aim, superparamagnetic iron oxide nanoparticles (SPIONs) as magnetic core were conjugated with MSNs to make a theranostic platform for in vivo monitoring of therapeutic response. Subsequently, DOX was encapsulated into the tunnels and its intelligent release in the tumor cells was facilitated via introducing $\mathrm{pH}$-responsive gold gatekeepers at the surface of MSNs. In the final step, a bi-functional PEG or DNA EpCAM aptamer (SYL3C; introduced by Song et al. [28]) was attached to prepared non-targeted and targeted DDSs, respectively. Incorporation of magnetic core for MRI imaging purposes, smart drug release at acidic $\mathrm{pH}$, and specific cancer cell targeting are three important considerations of this work. After fully characterization of prepared nanocarriers, the anticancer activity, cellular internalization, and cell death mechanism of non-targeted and targeted nanocarriers were compared in vitro. Finally, tumor inhibitory effects, 
biodistribution and possible side effects of the nanocarriers were evaluated in immunocompromised C57BL/6 mice bearing human HT-29 tumors.

\section{Results}

\section{Characterization}

In present study the main backbone, SPION@MSN, was first prepared and fully characterized. The FTIR spectra (Additional file 1: Figure S1) indicated the bands at $572 \mathrm{~cm}^{-1}$ corresponding to the $\mathrm{Fe}-\mathrm{O}$ bond, which was covered by the absorption bands of $\mathrm{Si}-\mathrm{O}$ $\mathrm{Si}$ and $\mathrm{Si}-\mathrm{O}$ at 1090 and $632 \mathrm{~cm}^{-1}$, respectively [29]. Moreover, AFM and SEM results demonstrated that nanocarriers had a uniform spherical morphology (Fig. 1A-D) and TEM images showed that SPION@ MSNs had a mean diameter of $\sim 20 \mathrm{~nm}$ with an open porous structure throughout the entire MSNs (Fig. 1E, F). As shown in Table 1, the mean zeta potential and particle size of SPION@MSNs were determined around $-19.52 \pm 1.85 \mathrm{mV}$ and $24.37 \pm 0.21 \mathrm{~nm}$, respectively. To prove the porous nature of the backbone, $\mathrm{N}_{2}$ absorption/desorption isotherms was performed and showed a typical type IV isotherm along with type-H1 hysteresis loop, giving a large surface area $\left(432.79 \mathrm{~m}^{2} / \mathrm{g}\right)$, pore volume $\left(1.23 \mathrm{~cm}^{3} / \mathrm{g}\right)$, and thin pore size $1.21 \mathrm{~nm}$ (Fig. 2A, B). Eventually, the magnetization curve demonstrated that the saturated magnetization value of SPION@MSNs was about 9.75 emu/g (Fig. 2C). After modification of core-shell surface with amine groups, the two bands at 3000 and $1556 \mathrm{~cm}^{-1}$ in the FTIR spectrum were emerged and assigned to $\mathrm{N}-\mathrm{H}$ and $\mathrm{C}=\mathrm{N}$ groups, respectively [30]. Moreover, presence of $\mathrm{N}$ element in the prepared formula was further confirmed by EDX elemental analysis (Additional file 1: Figure S2). The surface charge increased to $+15.35 \pm 3.23 \mathrm{mV}$, which was attributed to greatly abundant $\mathrm{N}_{2}$ groups strongly attached on the MSN surface and the average size observed in DLS was around $27.44 \pm 1.83 \mathrm{~nm}$. DOX loading in the porous cavity was performed by stirring DOX and SPION@MSNs- $\mathrm{NH}_{2}$ continuously at a $\mathrm{w} / \mathrm{w}$ ratio of $1: 1$. The encapsulation efficiency (EE\%) and drug loading capacity (LC\%) were about $98.65 \% \pm 0.88$ and $49.79 \% \pm 1.03$, respectively according to the data obtained by UV/Vis spectroscopy. In the FTIR spectra, absorption peaks at 3436 and $1728 \mathrm{~cm}^{-1}$ were observed due to additional hydroxyl and carbonyl groups, respectively [31] verifying the effective loading of DOX on the silica pores. The zeta potential and
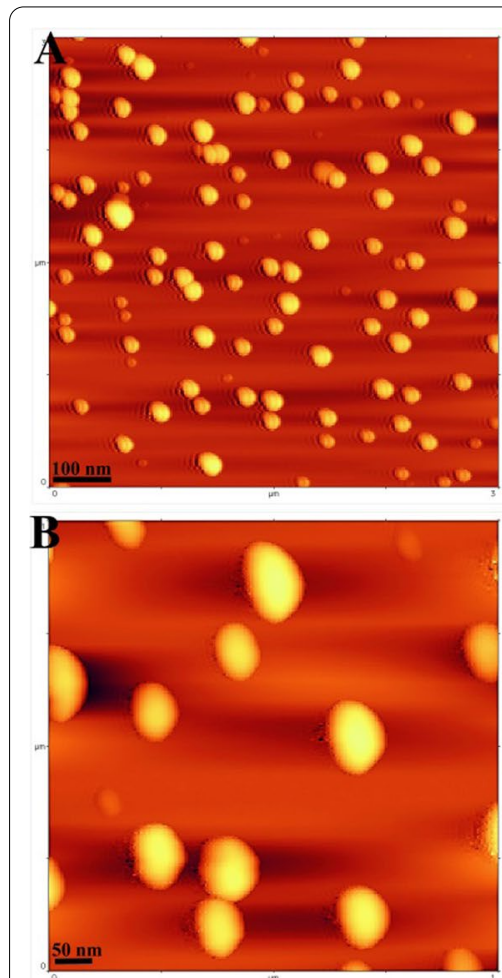
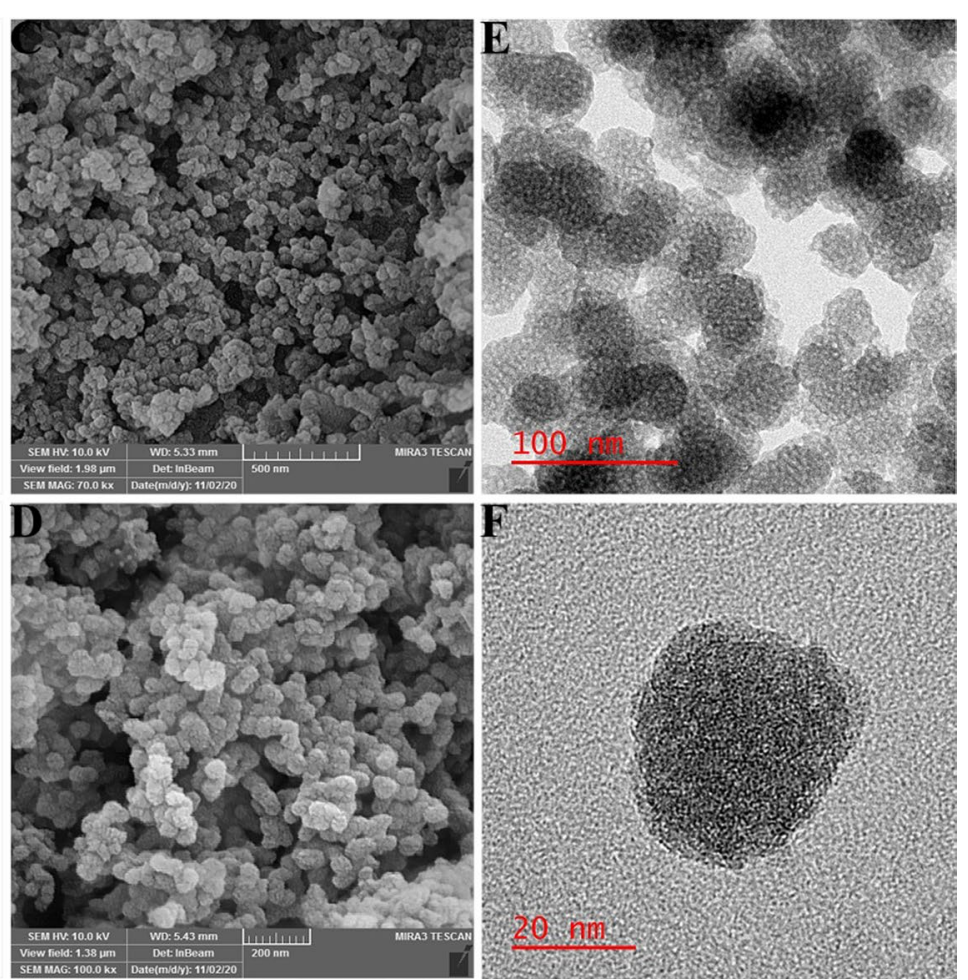

Fig. 1 Morphological characterizations of the backbone. A, B AFM, C, D SEM and E, F HR-TEM images of SPION@MSNs. AFM Atomic force microscopy, SEM Scanning electron microscopy, HR-TEM High resolution-transmission electron microscopy, SPION Superparamagnetic iron oxide nanoparticle, MSN Mesoporous silica nanoparticle 
Table 1 Characterization parameters of the prepared nanocarriers

\begin{tabular}{|c|c|c|c|c|c|}
\hline Samples & Zeta potential $(\mathrm{mV})$ & Particle size (nm) & $\begin{array}{l}\text { BET surface area } \\
\left(\mathrm{m}^{2} / \mathrm{g}\right)\end{array}$ & $\begin{array}{l}\text { Pore volume } \\
\left(\mathrm{cm}^{3} / \mathrm{g}\right)\end{array}$ & $\begin{array}{l}\text { BJH pore } \\
\text { diameter } \\
(\mathrm{nm})\end{array}$ \\
\hline SPION@MSNs & $-19.52 \pm 1.85$ & $24.37 \pm 0.21$ & 432.79 & 1.23 & 1.21 \\
\hline SPION@MSNs-NH 2 & $+15.35 \pm 3.23$ & $27.44 \pm 1.83$ & ND & ND & ND \\
\hline NPs@DOX & $-10.55 \pm 1.00$ & $32.38 \pm 3.33$ & ND & ND & ND \\
\hline Au-NPs@DOX & $-15.66 \pm 0.82$ & $39.71 \pm 5.45$ & 117.93 & 0.4 & 1.21 \\
\hline PEG-Au-NPs@DOX & $-18.50 \pm 1.22$ & $50.28 \pm 4.76$ & ND & ND & ND \\
\hline Apt-PEG-Au-NPs@DOX & $-19.79 \pm 2.18$ & $58.22 \pm 8.54$ & ND & ND & ND \\
\hline
\end{tabular}

Particle size was measured by dynamic light scattering (DLS). Data are expressed as mean $\pm S D$

BET Brunauer-emmett-Teller, BJH Barrett-Joyner-halenda, SPION Superparamagnetic iron oxide nanoparticle, MSN Mesoporous silica nanoparticle, DOX Doxorubicin, PEG Polyethylene glycol, Apt Aptamer, ND not determined
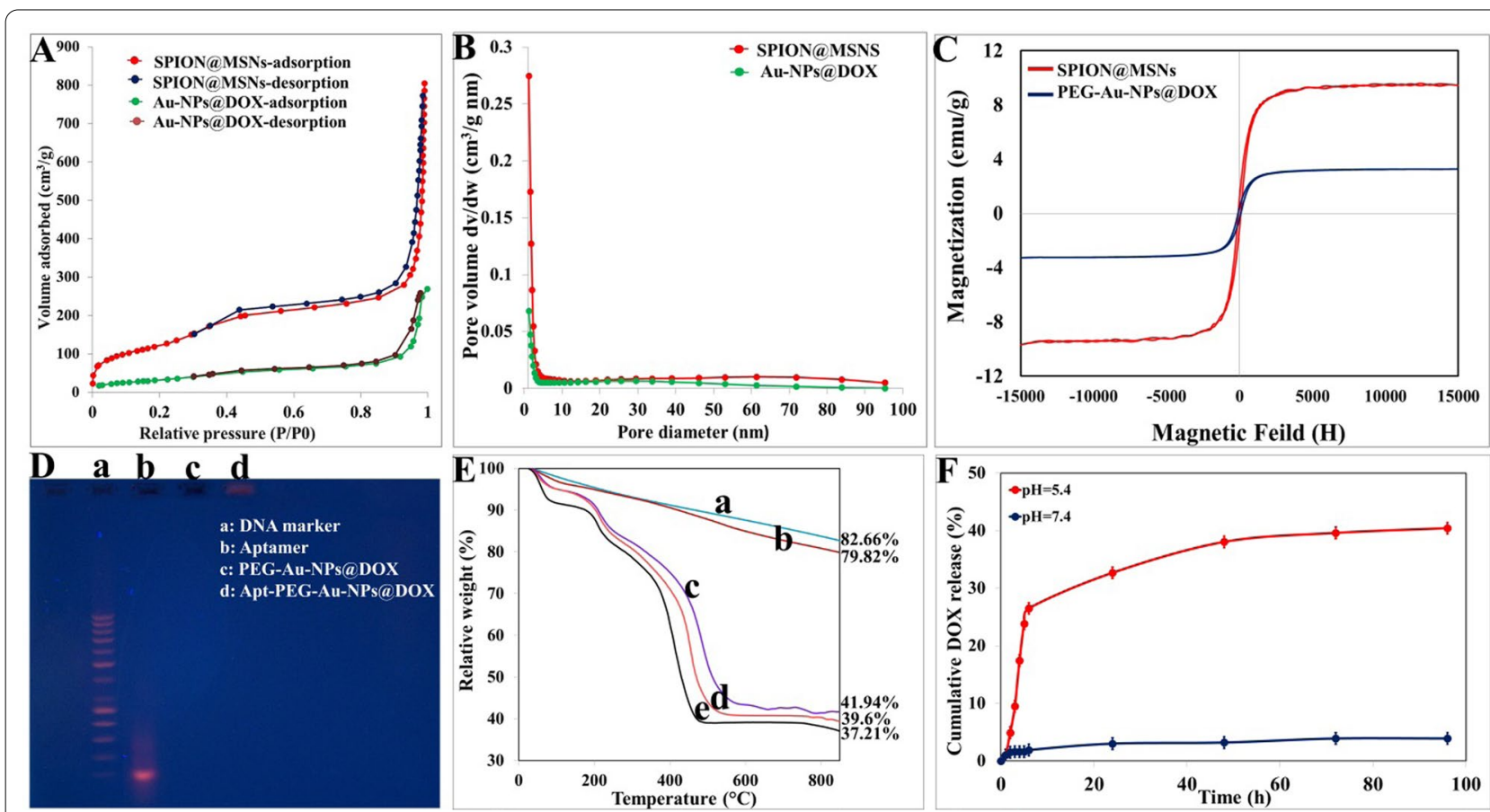

Fig. 2 Physicochemical characterization of nanocarriers. A $N_{2}$ adsorption/desorption isotherms and $\mathbf{B}$ pore size distribution of SPION@MSNs and Au-NPs@DOX.CVSM curves of SPION@MSNs and PEG-Au-NPs@DOX. D The conjugation of EpCAM aptamer was verified by electrophoresis. E TGA analysis curves of (a) SPION@MSNs, (b) SPION@MSNs-NH ${ }_{2}$ (c) Au-NPs@DOX, (d) PEG-Au-NPs@DOX and (e) Apt-PEG-Au-NPs@DOX.F In vitro DOX release profile of Au-NPs@DOX at pH 7.4 and pH 5.4 (data presented as mean \pm SD, $n=3$ ). SPION Superparamagnetic iron oxide nanoparticle, MSN Mesoporous silica nanoparticle, NP nanoparticle, DOX Doxorubicin, VSM Vibration sample magnetometer, PEG Polyethylene glycol, Apt Aptamer, EpCAM Epithelial cell adhesion molecule, TGA Thermal gravimetric analysis

particle size were recorded around $-10.55 \pm 1.00 \mathrm{mV}$ and 7.92 $\pm 3.33 \mathrm{~nm}$, respectively for NPs@DOX formula. In the next step, gold NPs as $\mathrm{pH}$ responsive gatekeepers were synthesized to cap the pore entrances of MSNs. The obtained gold gatekeepers were characterized on the basis of morphology, functional groups, maximum absorption wavelength $\left(\lambda_{\max }\right)$, particle size, and zeta potential (Additional file 1: Figure S3). The
TEM image showed the spherical shape and the uniform distribution of these particles. The FTIR spectrum indicated the bands at $3425,2919,1601,1400,1253$, and $1060 \mathrm{~cm}^{-1}$. The wave number at $3425 \mathrm{~cm}^{-1}$ was assigned to $\mathrm{O}-\mathrm{H}$ stretch and weak band at $2919 \mathrm{~cm}^{-1}$ indicated the presences of alkane groups on the gold NPs surface [32]. The wavenumbers at $1601,1400 \mathrm{~cm}^{-1}$ were attributed to $\mathrm{C}=\mathrm{C}$ and $\mathrm{C}-\mathrm{C}$ stretching vibrations, 
respectively. Moreover, the weak bands were formed at 1253 and $1060 \mathrm{~cm}^{-1}$ related to $\mathrm{C}-\mathrm{N}$ stretched aromatic and aliphatic amines, respectively [33]. The zeta potential and particle size of gold gatekeepers were found around $-17.66 \mathrm{mV}$ and $7.92 \pm 1.04 \mathrm{~nm}$, respectively and displayed a single absorption peak in the visible range at $520 \mathrm{~nm}$. After aggregation of gold capped NPs on the core-shell silica pores, a number of functional groups were detected. In this context, the absorption peaks at 1618 and $1210 \mathrm{~cm}^{-1}$ were assigned to $\mathrm{C}=\mathrm{C}$ and $\mathrm{C}-\mathrm{N}$, respectively. Furthermore, the zeta potential and particle size were determined around $-15.66 \pm 0.82 \mathrm{mV}$ and $39.71 \pm 5.45 \mathrm{~nm}$, respectively, and Au element was also indicated by EDX elemental analysis (Table 2). Pore-capping with gold NPs, $\mathrm{N}_{2}$ absorption/desorption isotherms still showed a type IV isotherm with type-H3 hysteresis loop, but their pore volume and surface area were markedly shifted to $0.4 \mathrm{~cm}^{3} / \mathrm{g}$ and $117.93 \mathrm{~m}^{2} / \mathrm{g}$, respectively (Fig. 2A, B). The decreased surface area of the Au-NPs@DOX with BET results along with reduction in $\mathrm{BJH}$ pore size in comparison with SPION@MSNs confirmed that the gold gatekeepers have entirely capped the core-shell silica pores. Incorporation of heterofunctional PEG on the surface of Au-NPs@DOX was further proved by a weak band at the wave number of $1414 \mathrm{~cm}^{-1}$ in the FTIR spectrum indicating the presence of $-\mathrm{COOH}$ stretched carboxyl groups [34]. Moreover, the size increase $(\sim 20 \mathrm{~nm})$, negative zeta potential, and reduced saturated magnetization value of PEG-Au-NPs@DOX may be attributed to the successful PEG coating. Upon EpCAM aptamer conjugation, a weak peak emerged at $2551 \mathrm{~cm}^{-1}$ assigned to the $-\mathrm{SH}$ group [35], thus verifying the effective decoration of EpCAM aptamer targeting on the nanocarriers surfaces. The mean zeta potential and particle size of final nanoconstructs were determined around $-19.79 \pm 2.18 \mathrm{mV}$ and $58.22 \pm 8.54 \mathrm{~nm}$, respectively. The successful conjugation of EpCAM aptamer on the surface of PEG-Au-NPs@DOX was further indicated by agarose gel electrophoresis. As seen in Fig. 2D, free EpCAM aptamer showed a band at the molecular weight of 50 bp, while PEG-Au-NPs@DOX did not show any band and Apt-PEG-Au-NPs@DOX stayed practically at the origin. Furthermore, TGA technique revealed a gradual increase in weight loss after each surface modification step (Fig. 2E). The weight loss values of SPION@MSNs, SPION@MSNs-NH $\mathrm{N}_{2}, \mathrm{Au}-\mathrm{NPs} @$ DOX, PEG-Au-NPs@DOX, and Apt-PEG-Au-NPs@ DOX were $17.34 \%, 20.18 \%, 58.06 \%$, 60.4\%, and $62.79 \%$ respectively, indicating the successful modification of each step.

\section{Drug release profile}

Intelligent release of cargoes at the region of interest is one of the most important steps to improve drug delivery behavior. For this aim, drug release experiments were designed in both acidic and physiological $\mathrm{pH}$, which were adjusted to 5.4 and 7.4, respectively. As shown in Fig. 2F, the highest DOX release was detected at acidic $\mathrm{pH}$ which is similar to the endosomes and was much faster than those at physiological pH. Moreover, the amount of DOX released from Au-NPs@DOX in acidic buffer was about $40.43 \%$ which was significantly higher than that at physiologic condition. In this regard, the results indicated that only 3.9\% of DOX was released from the Au-NPs@DOX in neutral medium over $96 \mathrm{~h}$.

\section{Blood hemolysis evaluation}

Covering the surface of nano-delivery systems with PEG as a well-known biodegradable polymer can greatly improve their behavior in the biological environments [18]. A hemolysis assay was conducted on PEG-AuNPs@DOX and compared with the backbone in order to evaluate their biocompatibility in the blood. As shown in Fig. 3, all tested concentrations $(12.5-200 \mu \mathrm{g} / \mathrm{ml})$ of PEGylated nanocarriers resulted in less than $2 \%$ hemolysis at 12 and $24 \mathrm{~h}$, demonstrating non-hemolytic activity. However, the hemolytic activity level of SPION@MSNs in RBCs reached to $3.5 \%$ and $2.4 \%$ at concentrations of 200 and $100 \mu \mathrm{g} / \mathrm{ml}$, respectively, at $24 \mathrm{~h}$. It seems that,

Table 2 Energy-dispersive X-ray (EDX) spectroscopy analysis of prepared nanocarriers

\begin{tabular}{lllllll}
\hline Samples & Si & Fe & N & C & O & Au \\
\hline SPION@MSNs & 35.21 & 2.58 & 0 & 6.63 & 55.58 & 0 \\
SPION@MSNs-NH 2 & 24.87 & 1.83 & 8.35 & 8.89 & 56.06 & 0 \\
Au-NPs@DOX & 7.96 & 0.69 & 5.72 & 16.84 & 27.75 & 41.05 \\
PEG-Au-NPs@DOX & 17.99 & 1.17 & 7.33 & 26.43 & 45.06 & 2.02 \\
\hline
\end{tabular}

The data are represented as weight percentage (W\%)

SPION Superparamagnetic iron oxide nanoparticle, MSN Mesoporous silica nanoparticle, DOX Doxorubicin, PEG Polyethylene glycol, Apt Aptamer 

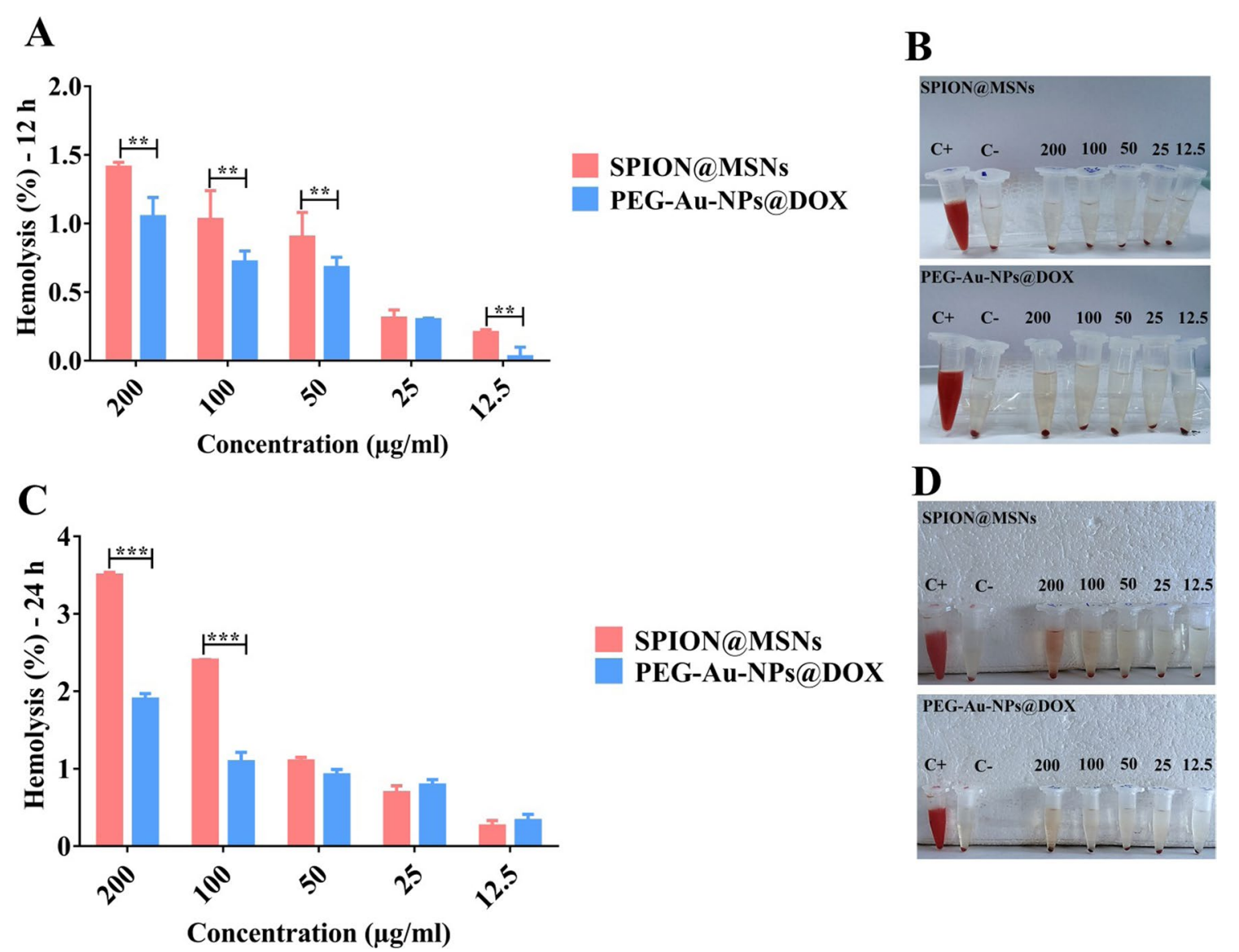

Fig. 3 Hemolysis assay on SPION@MSNs and PEG-Au-NPs@DOX nanocarriers. Comparison of hemolytic activity in red blood cells (RBCs) following A 12 and C $24 \mathrm{~h}$ incubation with various concentrations $(12.5-200 \mathrm{\mu g} / \mathrm{ml})$ of SPION@MSNs and PEG-Au-NPs@DOX at $37^{\circ} \mathrm{C}$. Data are expressed as mean $\pm \mathrm{SD}, \mathrm{n}=3,{ }^{* *} p<0.01$ and ${ }^{* * *} p<0.001$. Images of RBC s treated with mentioned concentration at $\mathbf{B} 12 \mathrm{~h}$ and $\mathbf{D} 24 \mathrm{~h}$. Positive control (distilled water, $\left.C^{+}\right)$, negative control (PBS, $\left.C^{-}\right)$, and nanocarrier suspensions $(200,100,50,25$ and $12.5, \mu \mathrm{g} / \mathrm{ml})$ are indicated. SPION Superparamagnetic iron oxide nanoparticle, MSN Mesoporous silica nanoparticle, PEG Polyethylene glycol, NP nanoparticle, Apt Aptamer, DOX Doxorubicin

PEG-modification reduces hemolytic activity and gives an excellent biosafety for intravenous injection.

\section{In vitro cytotoxicity}

In present study, we assessed the effects of conjugating EpCAM aptamer to nanocarriers, on their specificity to target EpCAM-expressing cells. The cytotoxicity of SPION@MSNs was first evaluated on both HT-29 and $\mathrm{CHO}$ cells to confirm the safety and nontoxicity of the backbone (data not shown). As shown in Fig. 4, there was a significant difference between toxicity of Apt-PEG-Au-NPs@DOX and PEG-Au-NPs@DOX as non-targeted formula on the EpCAM positive HT-29 cells in the range of $3.125-50 \mu \mathrm{g} / \mathrm{ml}$, at 24,48 , and $72 \mathrm{~h}$. Moreover, there was no significant difference between free DOX and targeted nanocarriers on HT-29 cells.
For $\mathrm{CHO}$ cells (EpCAM negative cells), Apt-PEG-AuNPs@DOX exhibited negligible toxicity in comparison with free DOX and PEG-Au-NPs@DOX. Furthermore, the $\mathrm{IC}_{50}$ values of free DOX and different formulations on both cell types following 24,48 , and $72 \mathrm{~h}$ treatments are calculated and presented in Table 3.

\section{Evaluating the effects of EpCAM aptamer on cellular internalization}

To assess the role of EpCAM aptamer on targeted cellular internalization of nanocarriers, we used both EpCAM positive and EpCAM negative cells. Tracking cellular uptake was evaluated using both flow cytometry and fluorescence microscopy. The cellular internalization by flow cytometry technique indicated higher uptake of AptPEG-Au-NPs@DOX in HT-29 cells as compared with PEG-Au-NPs@DOX, indicating the specific interaction 


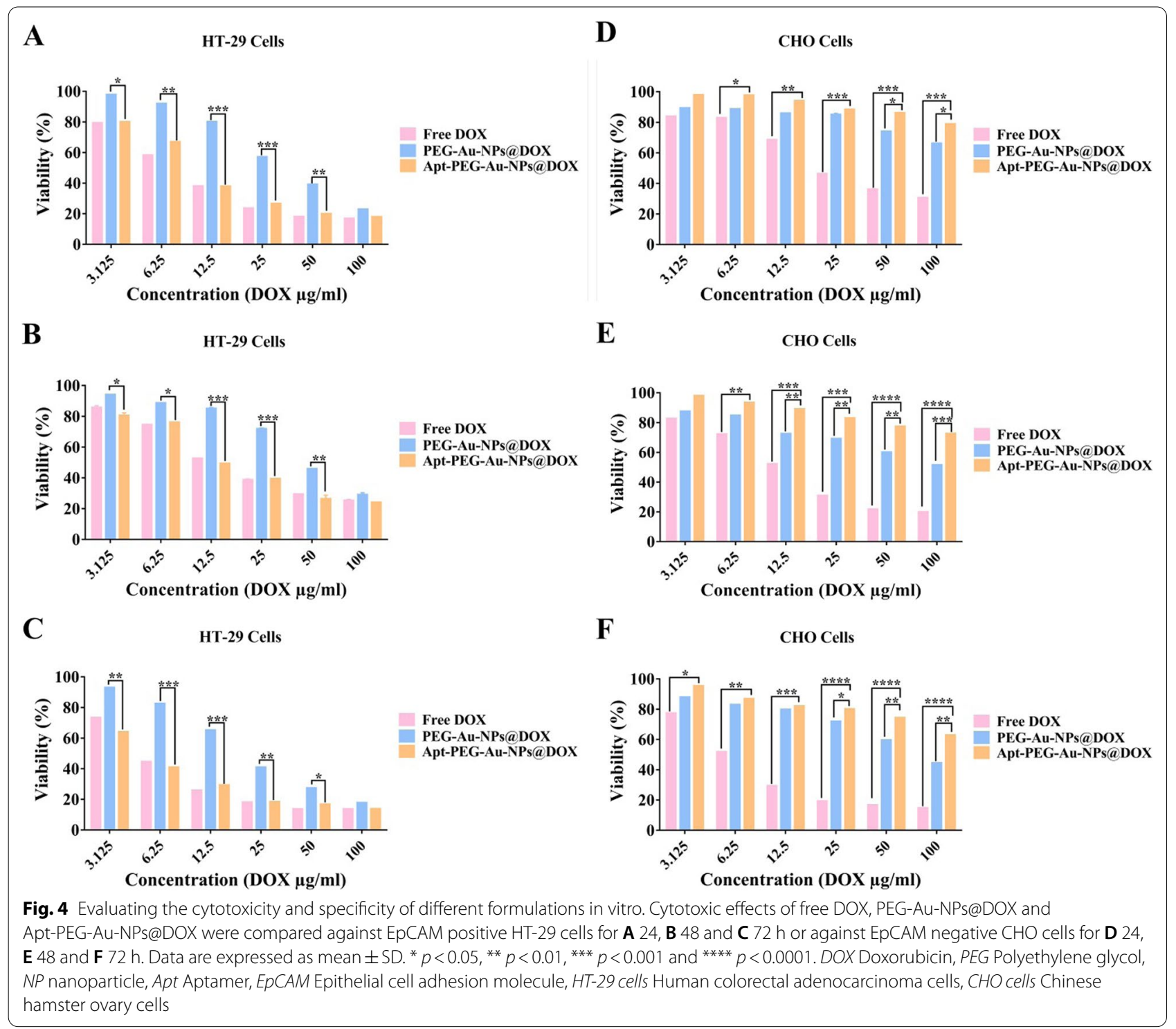

Table $3 I_{50}$ values of free DOX and nanocarriers on HT-29 and CHO cells during 24, 48, and $72 \mathrm{~h}$ of treatments

\begin{tabular}{|c|c|c|c|c|c|c|}
\hline \multirow[t]{2}{*}{ Treatments } & \multicolumn{3}{|c|}{$\mathrm{IC}_{50}(\mu \mathrm{g} / \mathrm{ml}) \pm \mathrm{SD}(\mathrm{HT}-29$ cells $)$} & \multicolumn{3}{|c|}{$\mathrm{IC}_{50}(\mu \mathrm{g} / \mathrm{ml}) \pm \mathrm{SD}(\mathrm{CHO}$ cells $)$} \\
\hline & $24 \mathrm{~h}$ & $48 \mathrm{~h}$ & $72 \mathrm{~h}$ & $24 \mathrm{~h}$ & $48 \mathrm{~h}$ & $72 \mathrm{~h}$ \\
\hline Free DOX & $8.86 \pm 1.78$ & $6.83 \pm 1.06$ & $4.89 \pm 1.06$ & $14.00 \pm 1.07$ & $9.63 \pm 1.08$ & $5.66 \pm 1.06$ \\
\hline PEG-Au-NPs@DOX & $33.90 \pm 1.07$ & $25.38 \pm 1.07$ & $15.99 \pm 1.05$ & $102.2 \pm 1.12$ & $77.01 \pm 1.10$ & $54.94 \pm 1.26$ \\
\hline Apt-PEG-Au-NPs@DOX & $9.72 \pm 1.08$ & $7.29 \pm 1.09$ & $5.52 \pm 1.09$ & $320.5 \pm 1.24$ & $243.2 \pm 1.27$ & $179.2 \pm 1.29$ \\
\hline
\end{tabular}

SPION Superparamagnetic iron oxide nanoparticle, MSN Mesoporous silica nanoparticle, DOX Doxorubicin, PEG Polyethylene glycol, Apt Aptamer

between EpCAM aptamer and its receptor (Fig. 5A). Moreover, the fluorescent intensity of Apt-PEG-AuNPs@DOX was lower in EpCAM ${ }^{-}$CHO cells (Fig. 5B). It should be noted that, there was no significant difference for DOX uptake in HT-29 and CHO cells due to its unspecific passive entrance through lipid bilayer. These observations were further confirmed by fluorescence microscopy. As shown in Fig. 5C, D the internalization 


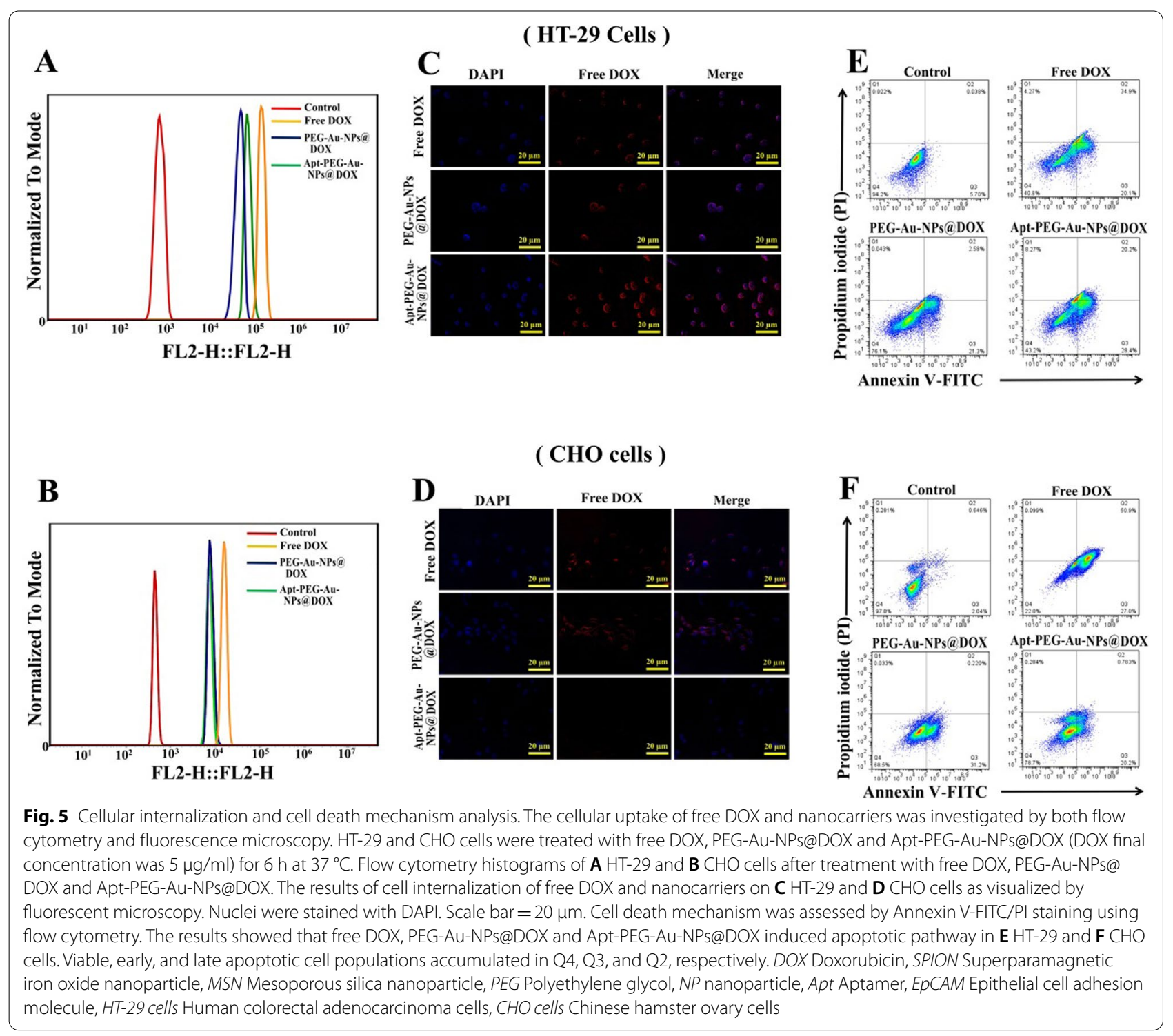

of the free DOX, PEG-Au-NPs@DOX and Apt-PEGAu-NPs@DOX are clearly observable from the red fluorescence of DOX molecules. In addition, internalization of targeted nanocarriers in HT-29 cells showed stronger red fluorescence compared to $\mathrm{CHO}$ cells, confirming the EpCAM aptamer mediated endocytosis of Apt-PEG-AuNPs@DOX nanocarriers.

\section{Assessment of cell death mechanism}

To investigate the mechanism of cell death induced by free DOX, PEG-Au-NPs@DOX and Apt-PEG-Au-NPs@ DOX in both HT-29 and CHO cells, Annexin V-FITC/PI staining was performed. Our data revealed that the viable cell population $(\mathrm{Q} 4)$ markedly decreased to $40.8 \%, 76.1 \%$, and $43.2 \%$ in free DOX, non-targeted and targeted nonocarriers-treated HT-29 cells compared with $94.2 \%$ in the control cells. Moreover, the percentage of early and late apoptotic cells $\left(\mathrm{Q}_{2}+\mathrm{Q}_{3}\right)$ increased from $5.7 \%$ in control to $55 \%, 23.8 \%$ and $48.6 \%$ in free DOX, PEG-Au-NPs@ DOX and Apt-PEG-Au-NPs@DOX groups, respectively when treated with the equivalent amounts of $5 \mu \mathrm{g} / \mathrm{ml}$ DOX for $48 \mathrm{~h}$ (Fig. 5E). On the other hand, the percentage of Q2+Q3 in CHO cells was 77.9\% for free DOX, while for PEG-Au-NPs@DOX and Apt-PEG-Au-NPs@ DOX it was about $31.4 \%$ and $20.9 \%$, respectively (Fig. 5F). The notable viable $\mathrm{CHO}$ cell populations following treatment with Apt-PEG-Au-NPs@DOX in comparison with free DOX confirmed that the aptamer conjugation had a critical role in reducing the toxicity of DOX against 

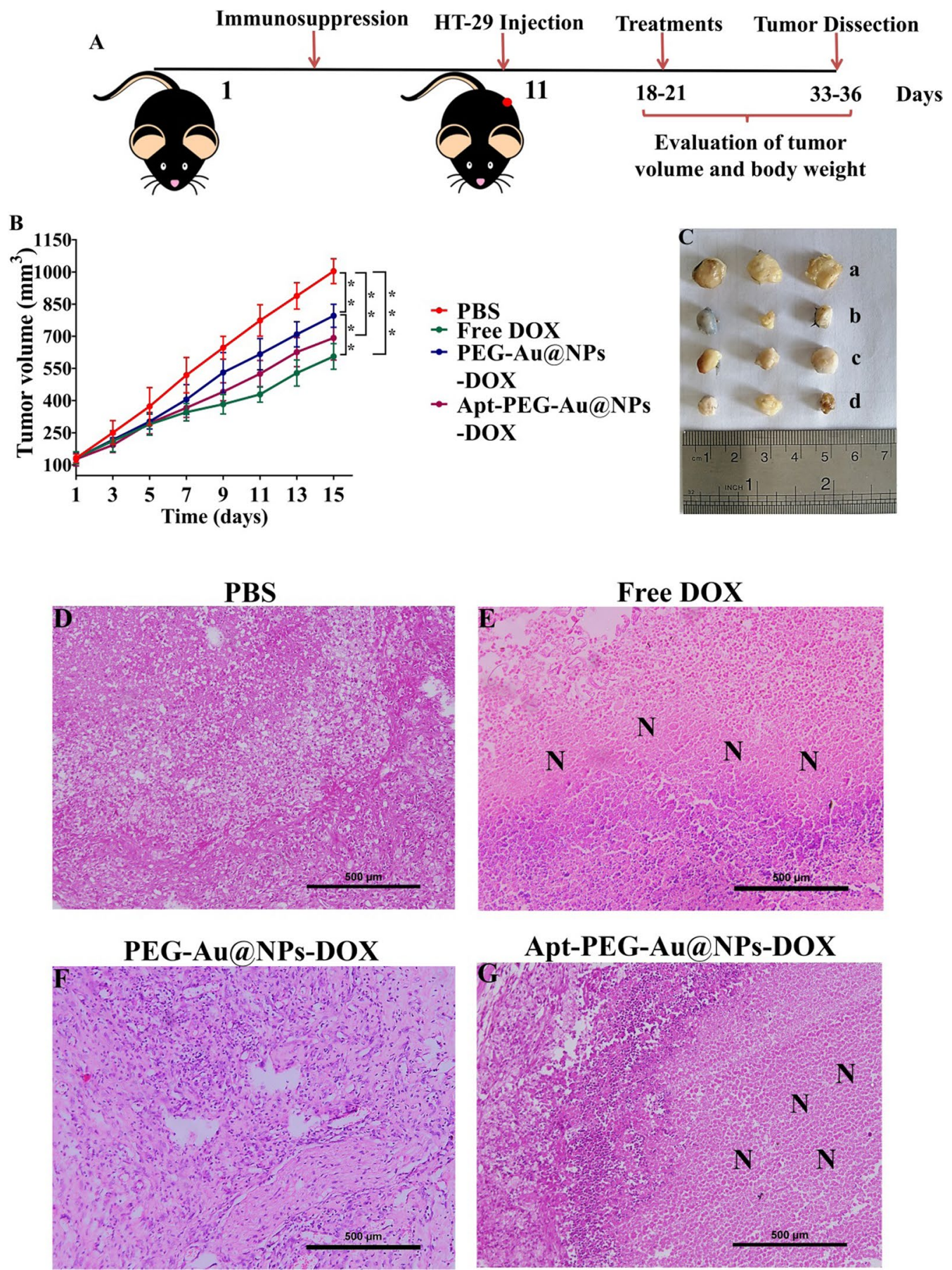

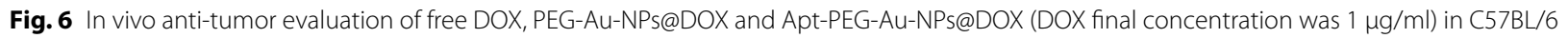
mice bearing HT-29 tumors. A Schematic illustration of the therapy regimen. B Tumor growth curves showed strongest inhibition of free DOX and Apt-PEG-Au-NPs@DOX. Data are expressed as mean $\pm \mathrm{SD}, \mathrm{n}=5 .{ }^{* *} p<0.01$ and ${ }^{* *} p<0.001$. C Tumor images in different experimental groups of (a) PBS, (b) free DOX, (c) PEG-Au-NPs@DOX and (d) Apt-PEG-Au-NPs@DOX treatments at day 15 post treatment. D H\&E staining of tumor tissues indicated high levels of necrotic cells in both free DOX and targeted nanocarries. Scale bar $=50 \mu \mathrm{m}$. " $\mathrm{N}$ " represents necrotic areas within the tumor mass. SPION Superparamagnetic iron oxide nanoparticle, MSN Mesoporous silica nanoparticle, PEG Polyethylene glycol, NP nanoparticle, Apt Aptamer, DOX Doxorubicin, H\&E Hematoxylin and eosin 
healthy cells and EpCAM aptamer can efficiently eradicate EpCAM positive HT-29 cells via inducing apoptotic cell death mechanism.

\section{In vivo anti-tumor activity of nanocarriers}

After administration of immunosuppression protocol in C57BL/6 mice, tumors were induced by injecting HT-29 cells, and the feasibility of nanocarriers for CRC therapy was investigated (Fig. 6A). As shown in Fig. 6B, tumor volume in the control group was markedly elevated by time and all treatment groups could effectively reduce tumor growth. The results indicated that free DOX and Apt-PEG-Au-NPs@DOX caused the strongest inhibition in tumor growth. Furthermore, the non-targeted group, receiving PEG-Au-NPs@DOX, exhibited a significantly lower tumor growth inhibition as compared with free DOX group $(p<0.01)$. The tumor size of free DOX and Apt-PEG-Au-NPs@DOX treated groups was notably smaller than those receiving PBS at the end of treatment (Fig. 6C). H \& E staining of the tumor tissues was carried out to further evaluate the anti-tumor activities of nanocarriers and showed the highest degree of tumor necrosis in both free DOX and Apt-PEG-Au-NPs@DOX treatment groups (Fig. 6D-G). These results confirm that the targeted nanocarriers had considerably higher antitumor properties in comparison with non-targeted formula owing to their tumor targeting potency.

\section{Biosafety evaluation}

H\&E staining of major organs including liver, kidney, spleen, heart, and lung, evaluating body weight and biodistribution of nanocarriers were performed to assess possible side effects. There were no obvious histological abnormalities in critical organs (Fig. 7A) and no noticeable changes in body weights (Fig. 7B) following treatment with non-targeted and targeted nanocarriers. In contrast, a remarkable decrease in body weight and local accumulation of inflammatory cells in the liver and kidney (black arrows) were noticed in free DOX treated group. It should be noted that, vacuolar degeneration of hepatocytes associated with sinusoidal dilatation and congestion (yellow arrows) were detected in the free DOX treated group. Furthermore, after intravenous injection of free DOX, PEG-Au-NPs@DOX and Apt-PEG-Au-NPs@DOX (DOX final concentration was $1 \mathrm{mg} / \mathrm{kg}$ ), the mice were sacrificed at certain time points, 12 and $24 \mathrm{~h}$ post injection, and major organs were harvested to evaluate nanocarriers biodistribution by in vivo imaging system (IVIS). The obtained results showed that free DOX was mainly accumulated in the liver, kidneys, heart, and tumor after $12 \mathrm{~h}$ and its fluorescence signal was more intensified for lung tissue at 24 h. PEG-Au-NPs@DOX and AptPEG-Au-NPs@DOX were also captured in the liver and kidneys at $12 \mathrm{~h}$. Interestingly, $24 \mathrm{~h}$ post injection, the distribution of targeted nanocarriers was less than non-targeted form in the kidney and lung, but more accumulated in the tumor tissue. Taken together, our results showed that Apt-PEG-Au-NPs@DOX was strongly distributed in the tumor with relatively low fluorescence intensity in normal tissues in comparison with free DOX indicating severe side effects (Fig. 8A, B).

\section{In vivo MRI}

SPION as an MRI contrast agent was conjugated at the center of nanocarriers to evaluate the imaging potential of prepared nanocarriers. T2 weighted MRI scans on C57BL/6 mice bearing HT-29 tumors were performed at 12 and 24 h post-administration of PEG-Au-NPs@DOX and Apt-PEG-Au-NPs@DOX. Based on quantitative analysis, MRI signal intensity value of targeted nanocarriers was markedly lower than non-targeted formula both at 12 and $24 \mathrm{~h}$ post injection due to the high concentration of SPION within the tumor tissue (Additional file 1: Table S1). Moreover, the signal intensities measured on MRI, confirmed high distribution of the Apt-PEG-AuNPs@DOX at the tumor region in comparison with PEGAu-NPs@DOX at $12 \mathrm{~h}$ after the injection (Fig. 8C-E). It should be noted that there was no significant differences between $12 \mathrm{~h}$, and $24 \mathrm{~h}$ of MRI scans; therefore, the images of $12 \mathrm{~h}$ are only reported. The encouraging MRI results confirmed that EpCAM aptamer mediated drug delivery to the malignant tissue through receptor-mediated mechanism.

\section{Discussion}

Globally, CRC accounts for the second cause of cancer related mortality both in women and men [1]. Nanotechnology based DDSs provide a powerful treatment package which can better suppress cancer cell proliferation and metastasis. There are a series of inorganic NPs such as polyoxometalates (POMs), covalent organic frameworks (COFs), metal organic frameworks (MOFs), SPIONs, and MSNs with considerable potentials in the treatment of CRC as evidenced by in vitro and in vivo studies. Various reports on POM applications in CRC therapy have displayed encouraging anti-cancer activity [36-40]. However, their long-term cytotoxicity on normal cells [41], non-specific interactions with biomolecules [42], their high negative charge [43], and lower thermodynamic and kinetic stability [44] are remarkable drawbacks that so far have prevented the practical applications of POMs. COFs and MOFs are new classes of porous materials, which have also received a great attention as efficient nanocarriers for drug delivery applications. However, they still face some challenges including 


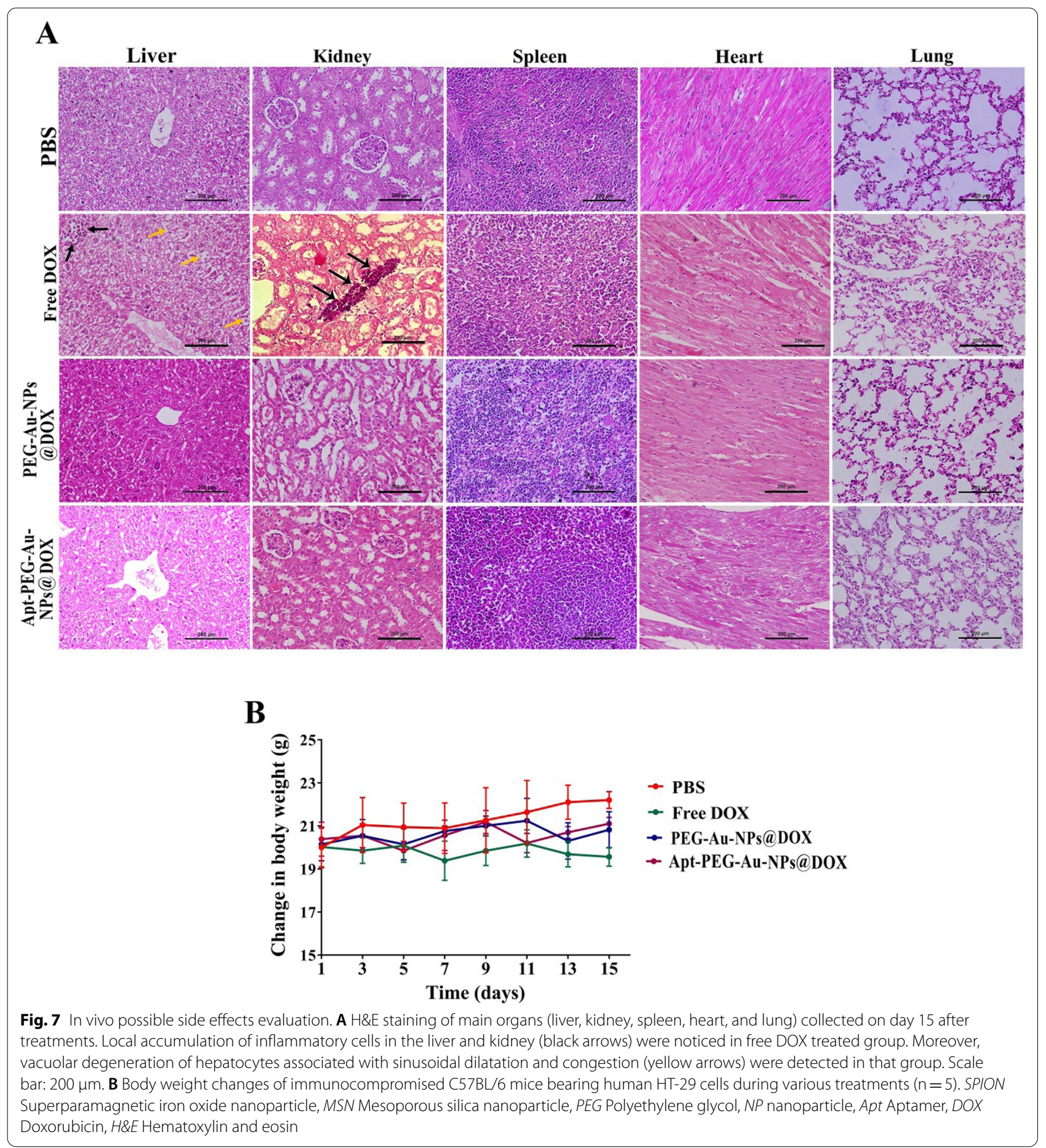

their toxicity, biodistribution, fate, and exertion which need to be well-defined prior to their further employment [20]. SPIONs have also been greatly attained owing to the unique magnetic properties for theranostic applications. These NPs may not be fully considered as nanocarriers due to low drug capacity and their toxicity concerns [45]. MSNs with distinctive physicochemical properties as mentioned earlier are attractive candidates for drug delivery applications. Particularly, silica which has been considered as "generally recognized as safe" (GRAS) by the United States Food and Drug Administration (FDA) [46]. We previously described various 


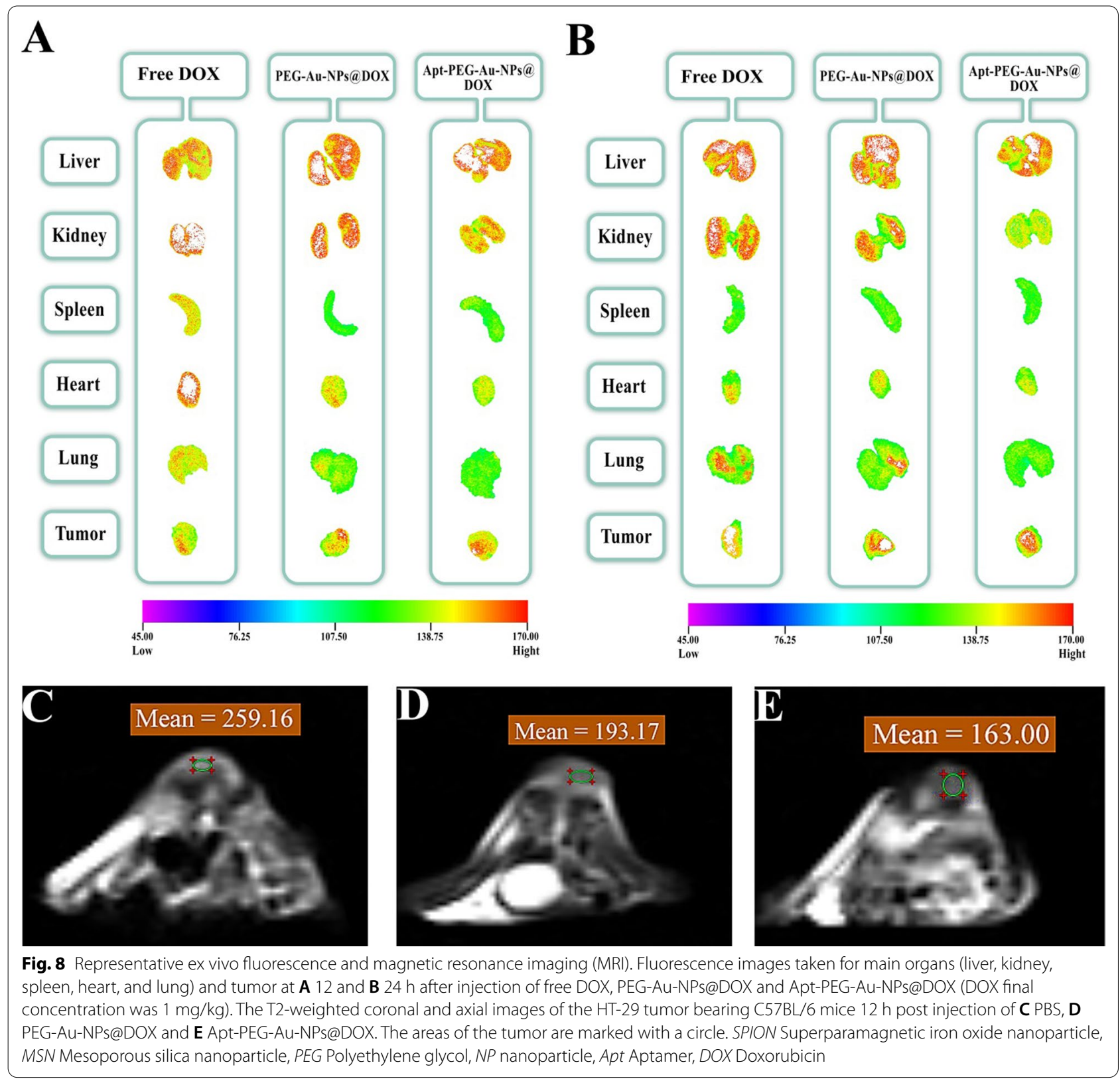

approaches to optimize physicochemical properties of DDSs as well as considering specific cancer cell receptors in the TME, which are two critical parameters that could significantly impact on drug delivery performance [20]. In this study, we used SPION as an MRI contrast agent within the MSN to provide a dual system for diagnosis and treatment in one-single nano-delivery platform. Generally, theranostic nanocarriers as current trend in cancer research have had a great impact in therapeutic field due to monitoring therapeutic efficacy during treatment and assessing possible side effects [47]. To this aim, we synthesized a novel theranostic platform for CRC therapy based on SPION@MSN which was further modified with gold gatekeepers, PEG, and EpCAM aptamer to increase therapeutic effects of DOX and decrease its severe side effects. We first synthesized spherical SPION@MSN nanocarriers with a size of $\sim 20 \mathrm{~nm}$ in diameter and negative zeta potential. After introducing amine groups, DOX was successfully encapsulated in the open channels of MSNs with EE\% and LC\% of $98.65 \% \pm 0.88$ and $49.79 \% \pm 1.03$, respectively. This high loading capacity of DOX is due to the open mesoporous structure of the MSNs confirming the results obtained by TEM analysis. In the next step, a formulation of NPs 
comprising gold gatekeepers were synthesized, characterized, and then used to block the pore entrances of MSNs to control the release of DOX. Presence of specific functional groups, detectable signal of Au atoms, changes of $\mathrm{N}_{2}$ absorption/desorption type, significant reduction of surface area, decrease in $\mathrm{BJH}$ pore size and significant weight loss strongly supported the successful capping of the MSNs. It was hypothesized that the electrostatic interactions between amine groups on the surface of MSNs and citrate groups on the gold gatekeepers under physiological condition are the main capping mechanism [16]. In order to evaluate the capping efficiency, DOX release profile was compared in the $\mathrm{pH} 5.4$ and $\mathrm{pH}$ 7.4. The results showed that the DOX release in acidic $\mathrm{pH}$ was significantly higher than that in the physiological $\mathrm{pH}$. In fact, protonation of amine groups in the citrate buffer can trigger dissociation of gold gatekeepers and subsequently lead to intelligent DOX release. As shown in Fig. 2F, two stages of drug release were observed from Au-NPs@DOX formulation in the citrate buffer. The first stage was rapid and burst within the first $6 \mathrm{~h}$ which might have been due to the quick diffusion of DOX from nanocarriers. The second stage of DOX release was slow and sustained in the next $24 \mathrm{~h}$. It can be concluded that $\mathrm{pH}$ sensitive gatekeepers were responsible for intelligent DOX release from DDSs which has a considerable impact on improving drug delivery behaviors. Analogously, Li et al. conjugated acid-labile acetal groups with gold gatekeepers in order to facilitate controlled release of cargo molecules from MSNs at low pH [14]. Similarly, Babaei et al. electrostatically assembled citrate-functionalized gold gatekeepers on the surface of MSNs for intelligent 5-FU release. Their results indicated that the release of 5-FU was augmented under acidic $\mathrm{pH}$ [16]. Coating the DDSs with PEG polymer was a routine method for ensuring solubility and dispersibility of nanocarriers, enhancing their circulatory half-life and blood biocompatibility [17]. In this study, heterofunctional PEG was used to establish thiol-Au linkage between PEG and gold gatekeeper resulting in improving drug delivery performance. The size of NPs was significantly increased from $39.71 \pm 5.45$ to $50.28 \pm 4.76 \mathrm{~nm}$ and the saturated magnetization value was markedly repressed in comparison with SPION@MSNs after PEGylation. This might be attributed to decrease in the magnetic core size and growth of the particle size followed by surface coating with PEG. Similarly, it was demonstrated that magnetic properties of SPIONs significantly decreased after introducing PEG as a coating agent due to reduction of saturation magnetization value [48]. Moreover, amount of oxygen and carbon elements was obviously elevated and the weight loss was also increased to $60.4 \%$ in the same temperature range. This finding in line with other mentioned results indicated the successful conjugation of PEG on the surface of nanocarriers. In this regard, numerous investigations were conducted to improve physicochemical properties of MSNs via PEG coating. For instance, long blood circulation with significantly lower entrapment in the liver, spleen, and lung was reported after PEGylation of MSNs [49]. Indeed, Desai et al. demonstrated that grafting both polyethylene imine (PEI) and PEG onto the surface of MSNs was helpful to overcome the challenges in oral administration, which led to increased blood half-life circulation and penetration into intestinal epithelial cells [50]. Other consequences of PEGylation strategy include improving colloidal stability and repression of hemolytic properties of MSNs [51]. With regard to these reports, hemolytic activity of PEG-Au-NPs@DOX was compared with SPION@MSNs in the concentration range of 12.5 to $200 \mu \mathrm{g} / \mathrm{ml}$ (Fig. 3). Similar to other reports, covering MSNs with PEG did not induce any observable hemolysis effect even at the highest particle concentrations which is less than the threshold value of $2 \%$ [52] at 12 and $24 \mathrm{~h}$. In contrast, SPION@MSNs exhibited slightly dose-dependent hemolytic behavior just at $24 \mathrm{~h}$. Obtained results are consistent with other studies showing hemolysis activity of silica NPs towards RBCs [53-55] and PEGylation could completely eliminate serious biosafety concerns of prepared nanocarriers in the given concentration range. In the next step, interaction between amine group of EpCAM aptamer and carboxylic acid group of heterofunctional PEG resulted in formation of targeted nanocarriers. Attachment of EpCAM aptamer to the surface of core-shell nanocarriers led to emerging a weak peak at $2551 \mathrm{~cm}^{-1}$ and caused a negative shift in zeta potential due to the presence of the thiol group of the aptamer. Moreover, agarose gel electrophoresis was performed to evaluate whether the EpCAM aptamer could bind to the surface of the nanocarriers. As shown in Fig. 2D, free aptamer moved along with the 50 bp DNA marker, whereas Apt-PEG-Au-NPs@DOX remained in the well due to their heavy weight. This result confirmed the effective decoration of nanocarriers with EpCAM aptamer and formation of targeted formula with the average size of $58.22 \pm 8.54 \mathrm{~nm}$.

In order to validate the feasibility of prepared nanocarriers for drug delivery purposes, the anti-cancer efficacy of non-targeted (PEG-Au-NPs@DOX) and targeted (Apt-PEG-Au-NPs@DOX) formulas was compared both in vitro and in vivo in the second part of the study. It has been demonstrated that HT-29 exhibited a high EpCAM expression [56] in comparison with $\mathrm{CHO}$ cells which were negative for this marker [57, 58]; so HT-29 and CHO cells were chosen for in vitro studies. The anti-cancer efficacy of free DOX, 
PEG-Au-NPs@DOX and Apt-PEG-Au-NPs@DOX was investigated by MTT assay. As evident in Fig. 4, treatment with free DOX and both nanocarriers induced a time- and dose-dependent decrease in viability of HT-29 cells. Moreover, there was a significant difference between anti-cancer activity of non-targeted and targeted nanocarriers against HT-29 cells during 24, 48, and $72 \mathrm{~h}$. Remarkable anti-cancer activity of AptPEG-Au-NPs@DOX against HT-29 cells beside the lack of notable cytotoxicity on $\mathrm{CHO}$ cells as compared with PEG-Au-NPs@DOX, emphasized the critical role of targeting moiety for specific recognition of receptors and selective delivery of anti-cancer drugs. On the other hand, we found that the free DOX was ineffective against CRC owing to the similar cytotoxic effects on EpCAM positive and negative cells which confirm its severe side effects. Our results are consistent with other reports demonstrating that arming nanocarriers with targeting moieties is an effective strategy to induce selective cytotoxicity in target cancerous cells. For instance, Sakhtianchi et al. reported significant difference $(p<0.05)$ between toxicity profile of DOXPEG-MMSNs and DOX-APT-PEG-MMSNs. Their results indicated that targeted nanocarriers were more toxic in compression with non-targeted nanocarriers in case of MCF-7 cells [59]. Moreover, Siminzar et al. revealed higher cytotoxicity of targeted nanocarriers(DOX-SPION@SiO ${ }_{2}$-MUC-1) against MCF-7 cells as compared to the non-targeted structure (DOXSPION@SiO ${ }_{2}$ ) [60]. Tracking cellular internalization of nanocarriers by quantitative and qualitative analyses demonstrated the higher uptake of Apt-PEG-AuNPs@DOX in HT-29 cells, compared with CHO cells, further confirming the MTT results. Moreover, free DOX was quickly distributed into HT-29 and CHO cells without any specificity so it had the highest cellular uptake and toxicity among the nanocarriers. These results confirm that the presence of EpCAM aptamer on the surface of DDSs could augment the internalization process in the EpCAM positive cells and minimize off-target effects. Furthermore, the results of cell death mechanism clearly showed that Apt-PEG-AuNPs@DOX selectively induced more apoptotic cell death in HT-29 as compared to PEG-Au-NPs@DOX which is consistent with cytotoxicity and uptake results (Fig. 5). It can be concluded that the arming of MSNs with EpCAM aptamer can improve drug delivery performance leading to markedly greater cytotoxicity, cellular uptake and increased apoptotic level in the CRC cells overexpressing EpCAM biomarker. In the past decade, development of targeted MSNs has had a great impact on specific cancer cell recognition and increasing the therapeutic efficacy. For instance, it has been shown that recruiting the AS1411 and mucin-1 (MUC1 ) as conventional targeting aptamers on the surface of MSNs can significantly increase selective delivery of DOX and strong toxicity against MCF-7 breast cancer cells $[59,60]$. Hyaluronic acid (HA) is another targeting ligand, which has been widely conjugated to the MSNs for specific recognition of CD44 overexpressing colon cancer cells [61-63]. Moreover, there have been several reports that combined EpCAM aptamer as targeting element with MSNs to enhance the cytotoxic effects of anti-cancer drugs against CRC cells. Towards this end, in vitro results of Xie et al. demonstrated that modification of MSNs with EpCAM aptamer could augment cellular uptake and increase cytotoxicity of the DOX on SW620 cells as compared with non-targeted MSNs [25]. Moreover, it has been shown that combination of DNA EpCAM aptamer with MSNs can be considered as a favorable drug delivery platform for CRC therapy $[26,64]$. Eventually, an immunocompromised C57BL/6 mouse model was used to compare the therapeutic efficacy of nanocarriers and evaluate their possible side effects. In vivo results indicated that free DOX and Apt-PEG-Au-NPs@DOX could remarkably suppress tumor growth as compared with non-targeted group demonstrating high levels of tumor necrosis (Fig. 6). Biosafety evaluation indicated the body weight loss, tissue damages, and non-specific accumulation in normal tissues following the free Dox treatment; confirming its severe side effects. In this context, presence of EpCAM aptamer, as targeting ligand, in the treatment group could significantly decrease DOX toxicity as shown with no weight loss, lack of normal tissue damages, and significant intratumoral saturation (Figs. 7 and 8). Generally, EpCAM biomarker is closely associated with cancer cell proliferation [65] and migration [66], thus development of DDSs which target the EpCAM receptors may lead to reduction of cancer cell metastasis. In vivo data showed that Apt-PEG-Au-NPs@DOX presented better anti-cancer effects in comparison with PEG-Au-NPs@DOX. This could be attributable to passive accumulation of non-targeted nanocarriers at the tumor tissue while, targeted nanocarriers accumulated via both passive and active targeting. Generally, several studies have used different types of theranostic nanocarriers for therapeutic purposes. In order to get a comprehensive evaluation, the results were compared with other studies and summarized in Table 4. It can be concluded that prepared theranostic NPs with $\sim 58 \mathrm{~nm}$ diameter must have circulated safely in the blood due to the presence of the PEG polymer on their surface and reached the TME through EPR effect. It has been shown that nanocarriers smaller than $100 \mathrm{~nm}$ can easily pass the vessel gaps in the TME [67] and we expect the 
Table 4 Examples of theranostic nanocarriers used for therapeutic purposes

\begin{tabular}{|c|c|c|c|c|c|c|c|}
\hline $\begin{array}{l}\text { Theranostic } \\
\text { nanocarriers }\end{array}$ & Contrast agents & Particle size & $\begin{array}{l}\text { Therapeutic } \\
\text { agents }\end{array}$ & $\begin{array}{l}\text { Targeting } \\
\text { moieties }\end{array}$ & Cancer cell lines & Animal models & References \\
\hline YVO4:Eu3+@MSN & YVO4:Eu3 + & $\sim 375 \mathrm{~nm}$ & DOX & None & HeLa cells & None & {$[68]$} \\
\hline $\begin{array}{l}\mathrm{YVO} 4: \mathrm{Eu} 3 \mathrm{C} \text { and } \mathrm{Fe} \\
{ }_{3} \mathrm{O}_{4}-\mathrm{MSN}\end{array}$ & YVO4:Eu3C & $\sim 50 \mathrm{~nm}$ & DOX & None & $\begin{array}{l}\text { HeLa and MCF-7 } \\
\text { cells }\end{array}$ & None & {$[69]$} \\
\hline M-MSN & $\mathrm{MnFe}_{2} \mathrm{O}_{4}$ & 100-150 nm & DOX & Folic acid & HeLa cells & Albino mice & [70] \\
\hline pMMSN & $\begin{array}{l}\text { Not used for imag- } \\
\text { ing purpose }\end{array}$ & $175.7 \pm 11.4 \mathrm{~nm}$ & DOX & None & None & $\begin{array}{l}\text { S180 tumor bear- } \\
\text { ing mice }\end{array}$ & [71] \\
\hline MMS & $\begin{array}{l}\text { Not used for imag- } \\
\text { ing purpose }\end{array}$ & $\sim 150 \mathrm{~nm}$ & DOX & None & HeLa cells & None & [72] \\
\hline IONP & IONP & $\sim 4-10 \mathrm{~nm}$ & DOX & Folic acid & HeLa cells & None & {$[72]$} \\
\hline MSN-IONP & IONP & $60 \pm 2 \mathrm{~nm}$ & None & None & LNCaP cells & $\begin{array}{l}\text { LNCaP tumor } \\
\text { bearing nude } \\
\text { mice }\end{array}$ & [73] \\
\hline Au@SPIONs & SPION & $\sim 19 \mathrm{~nm}$ & None & MUC-1 aptamer & $\begin{array}{l}\text { L929 and HT- } 29 \\
\text { cells }\end{array}$ & None & [74] \\
\hline GoMe & Gold nanoparticle & $50.87 \pm 10.69 \mathrm{~nm}$ & DOX & None & A2058 cells & $\begin{array}{l}\text { Lung tumor bear- } \\
\text { ing FVB mice }\end{array}$ & [75] \\
\hline SPION & SPION & Not reported & None & Hyaluronic acid & MDA-MB-231 cells & $\begin{array}{l}\text { MDA-MB-231 } \\
\text { tumor-bearing } \\
\text { mice }\end{array}$ & {$[76]$} \\
\hline Au@MSN & Gold nanoparticle & $\sim 63.12 \mathrm{~nm}$ & $5-\mathrm{FU}$ & EpCAM aptamer & HepG2 cells & $\begin{array}{l}\text { HepG2 tumor } \\
\text { bearing } \\
\text { nude mice }\end{array}$ & [16] \\
\hline SPION & SPION & $\sim 58 \mathrm{~nm}$ & siRNA & Folic acid & SGC-7901 cells & None & {$[77]$} \\
\hline MMSN & $\begin{array}{l}\text { Not used for imag- } \\
\text { ing purpose }\end{array}$ & $18.68 \pm 2.31 \mathrm{~nm}$ & Epi & None & C26 cells & $\begin{array}{l}\text { C26 tumor bearing } \\
\text { mice }\end{array}$ & [78] \\
\hline SPION & SPION & Below 170 nm & DOX & Folic acid & $\begin{array}{l}\text { HCT116 and } \\
\text { MCF-7 cells }\end{array}$ & $\begin{array}{l}\text { HCT116 tumor } \\
\text { bearing mice }\end{array}$ & [79] \\
\hline MSN-EuGd & EuGd & $\sim 120 \mathrm{~nm}$ & None & $\begin{array}{l}\text { Hyaluronic acid } \\
\text { and TAT peptide }\end{array}$ & A549 cells & None & {$[80]$} \\
\hline MMSNs & SPION & $89.88 \pm 4.7 \mathrm{~nm}$ & DOX & AS1411 aptamer & MCF-7 cells & None & [59] \\
\hline SPION@MSN & $\begin{array}{l}\text { Not used for imag- } \\
\text { ing purpose }\end{array}$ & $\sim 27-50 \mathrm{~nm}$ & DOX & MUC-1 aptamer & MCF-7 cells & None & {$[60]$} \\
\hline HMSNsCS-CuS & CuS & $150 \pm 13 \mathrm{~nm}$ & DOX & None & MDA-MB-231 cells & $\begin{array}{l}\text { MDA-MB-231 } \\
\text { tumor bearing } \\
\text { nude mice }\end{array}$ & {$[81]$} \\
\hline
\end{tabular}

MSN Mesoporous silica nanoparticle, DOX Doxorubicin, $M-M S N$ Mesoporous silica-coated superparamagnetic manganese ferrite (MnFe $\mathrm{O}_{4}$ ) nanoparticle, $p M M S N$ Phosphonate-terminated magnetic mesoporous nanoparticle, MMS Magnetic mesoporous silica nanoparticle, IONP Iron oxide nanoparticle, MUC-1 Mucin 1, GoMe Gold/Mesoporous silica hybrid nanoparticle, EpCAM Epithelial cell adhesion molecule, MMSN Magnetic mesoporous silica nanoparticle, Epi Epirubicin, HMSNsCS-CuS Mesoporous silica nanoparticles gated by chitosan-copper sulfide composites

designed nanocarriers to have effectively penetrated within the tumor. At this stage, incorporation of SPION as an MRI contrast agent makes it possible to track intratumoral accumulation of nanocarriers. EpCAM aptamer specifically interacts with EpCAM receptor in the TME and facilitates internalization of the targeted nanocarriers. Loaded DOX would be released into the cytosol under acidic environment and results in cancer cell death, while reducing the side effects.

\section{Conclusion}

Several strategies need to be considered in designing nanocarriers to improve drug delivery performance and therapeutic outcomes. Overall, we developed a biocompatible, $\mathrm{pH}$-sensitive, and targeted theranostic platform based on MSNs, which can effectively deliver DOX to human CRC cells, maximize anti-cancer activity, and minimize off-target toxicities. In this context, Apt-PEGAu-NPs@DOX offered numerous advantages as a therapeutic platform in CRC therapy including (1) in vivo tracking, (2) high drug loading capacity, (3) biocompatibility, (4) intelligent and sustained drug release at acidic $\mathrm{pH}$, (5) long blood circulation to passive accumulation 
at tumor site (6) appropriate size for tumor penetration $(\sim 58 \mathrm{~nm})$, and (7) capability of targeting HT-29 tumors by active targeting mechanisms. The current multifunctional DDS constitutes a favorable replacement for CRC therapy, however further studies are required before it can reach the clinic.

\section{Experimental section Materials}

N-hydroxysuccinimide (NHS), 1-ethyl-3-(3-dimethylaminopropyl) carbodiimide hydrochloride (EDC), n-cetyltrimethylammonium bromide $(\mathrm{CTAB}), \mathrm{Fe}_{3} \mathrm{O}_{4}$, chloroauric acid $\left(\mathrm{HAuCl}_{4}\right)$, trisodium citrate, tetraethyl orthosilicate (TEOS), (3-aminopropyl)triethoxysilane (APTES), and 4',6-diamidino-2-phenylindole (DAPI) were purchased from Sigma-Aldrich Co. (Germany). Heterofunctional PEG polymer with a terminal thiol and carboxylic acid functional groups (SH-PEG-COOH, Mw: 3500) was purchased from GemChem (USA). Roswell Park Memorial Institute 1640 (RPMI 1640) medium, fetal bovine serum (FBS) and penicillin/streptomycin were purchased from Gibco (Scotland). FITC Annexin V apoptosis detection kit with propidium iodide (PI) was obtained from BioLegend (USA). Trypsin and 3-(4,5-dimethylthiazol2-yl)-2, 5-diphenyltetrazolium bromide (MTT) were purchased from Tinab Shimi (Iran). Doxorubicin hydrochloride (DOX) was purchased from Euroasia Co. Ltd. (India). Matrigel ${ }^{\circledR}$ matrix (DLW354263) was obtained from Corning Inc. (USA). The 48 mer EpCAM DNA aptamer (sequence: 5'-amine CACTACAGAGGTTGC GTCTGTCCCACGTTGTCATGGGGGGTTGGCCTG -3'-thiol) was synthesized by MicroSynth (Switzerland). DNA marker (50 bp), tris-borate-EDTA (TBE) buffer, and agarose powder were purchased from DENAzist Asia (Iran). Ethidium bromide was purchased from SinaClon (Iran). Furthermore, absolute ethanol, chemical reagents, and other solvents were obtained from Merck (Germany).

Human colon cancer cell line (HT-29) and Chinese hamster ovary $(\mathrm{CHO})$ cell line were obtained from Pasteur Institute, Tehran, Iran and cultured in RPMI 1640 medium supplemented with $10 \%(\mathrm{v} / \mathrm{v}) \mathrm{FBS}$ at $37{ }^{\circ} \mathrm{C}$ containing $5 \% \mathrm{CO}_{2}$ in a humidified incubator.

\section{Synthesis procedures}

\section{Synthesis of magnetic mesoporous silica NPs (SPION@MSNs)}

SPION@MSN core-shell nanocarriers were prepared according to the published method by Yang et al. [82]. $\mathrm{Fe}_{3} \mathrm{O}_{4}(200 \mathrm{mg})$ was dispersed in the mixture solution of ethanol $(80 \mathrm{ml})$ and deionized water $(20 \mathrm{ml})$ followed by drop wise addition of TEOS (1 ml) under nitrogen gas condition at $40{ }^{\circ} \mathrm{C}$ for $2 \mathrm{~h}$. In the next step, magnetic NPs were separated using centrifugation $(6000 \mathrm{~g}$ for $15 \mathrm{~min}$ ) and re-dispersed in a mixed solution containing deionized water $(20 \mathrm{ml}), \mathrm{NH}_{3}(1 \mathrm{ml})$ and CTAB $(0.75 \mathrm{~g})$. The solution was heated up to $60{ }^{\circ} \mathrm{C}$ under vigorous stirring $(100 \mathrm{rpm})$ followed by TEOS $(2.5 \mathrm{ml})$ addition and preserved for $2 \mathrm{~h}$ under reflux condition. The resultant product was collected by centrifugation and washed three times with ethanol. In order to completely remove $\mathrm{CTAB}$ from MSNs, the calcination was performed at $600{ }^{\circ} \mathrm{C}$ for $5 \mathrm{~h}$.

\section{Synthesis of $\mathrm{NH}_{2}$-modified SPION@MSNs}

SPION@MSN core-shell nanocarriers (16 mg) were dispersed in ethanol $(16 \mathrm{ml})$, followed by the addition of APTES $(60 \mu \mathrm{l})$ and the mixture was stirred at room temperature for $24 \mathrm{~h}$. The SPION@MSNs- $\mathrm{NH}_{2}$ were collected by centrifugation $(10,000 \mathrm{~g}$ for $20 \mathrm{~min})$ to remove excess APTES and solvent, followed by washing the mixture twice with ethanol [83].

\section{Loading of DOX into the $\mathrm{NH}_{2}$-modified SPION@MSNs}

SPION@MSNs- $\mathrm{NH}_{2}$ (2 mg) were suspended in $1 \mathrm{ml}$ DOX solution and the mixture sonicated, and then stirred for $48 \mathrm{~h}$ at room temperature. Then, the resulting formula SPION@MSNs- $\mathrm{NH}_{2} @ \mathrm{DOX}$ (that is abbreviated as NPs@DOX) was centrifuged (17,000g for $15 \mathrm{~min})$ and the absorbance of supernatant (unloaded free DOX) was determined by ultraviolet-visible spectrophotometry (UV/Vis; Eppendorf, Germany) at $480 \mathrm{~nm}$ according to the standard curve of known concentrations of DOX solutions. Finally, DOX encapsulation efficiency (EE\%) and drug loading capacity (LC\%) were calculated as follows [84]:

$$
\begin{aligned}
& \mathrm{EE} \%=\frac{\text { Total } \mu \mathrm{g} \text { of DOX }-\mu \mathrm{g} \text { of DOX in supernatant }}{\text { Total } \mu \mathrm{g} \text { of DOX }} \times 100 \\
& \mathrm{LC} \%=\frac{\text { Total } \mu \mathrm{g} \text { of DOX }-\mu \mathrm{g} \text { of DOX in supernatant }}{\text { Total } \mu \mathrm{g} \text { of nanocarriers }} \times 100
\end{aligned}
$$

\section{Synthesis of gold capped NPs (Au-NPs@DOX)}

Gold NP can be used as an intelligent gatekeeper to control the release of DOX from SPION@MSN. In this regard, freshly prepared $\mathrm{HAuCl}_{4}(300 \mathrm{ml} ; 0.5 \mathrm{mM})$ was heated with a heating mantle under vigorous stirring. When the temperature reached $80{ }^{\circ} \mathrm{C}$, freshly prepared trisodium citrate solution $(30 \mathrm{ml} ; 38.8 \mathrm{mM})$ was added into the aqueous solution of $\mathrm{HAuCl}_{4}$. The color of solution changed immediately to black gray and then to pink after $2-4 \mathrm{~min}$. The solution was kept at $70{ }^{\circ} \mathrm{C}$ for $5 \mathrm{~min}$ and then cooled down while being gently stirred [85]. Gold NPs were investigated by transmission electron microscopy (TEM; Philips, Germany), Fouriertransform infrared spectrum (FTIR; Thermo, USA), UV/ Vis spectroscopy, zeta potential measurements (CAD 
Instruments; France), and dynamic light scattering (DLS; Cordouan Technologies, France).

Prepared gold NPs $(1 \mathrm{ml} ; 0.2 \mathrm{mM})$ were added to suspension of NPs@DOX (1 ml; $2 \mathrm{mg} / \mathrm{ml})$ and stirred for $24 \mathrm{~h}$ at room temperature. The aggregation of gold capped gatekeepers on core-shell silica pores was found to depend strongly on electrostatic interactions between citrate and amine groups.

\section{Synthesis of PEG-Au-NPs@DOX and Apt-PEG-Au-NPs@DOX}

$6 \mathrm{mg}$ of heterofunctional PEG (SH-PEG-COOH) was added into the suspension and allowed to react for $24 \mathrm{~h}$ at room temperature under vigorous stirring. The thiol group strongly binds to the surfaces of Au-NPs through $\mathrm{Au}-\mathrm{S}$ linkage in order to prepare non-targeted nanocarriers. In the next step, amine functionalized EpCAM DNA aptamer was covalently attached to carboxylic group of PEG on the surface of PEG-Au-NPs@DOX utilizing EDS and NHS as activating agents. For this aim, EDS $(3.27 \mathrm{mg})$ and NHS $(1.96 \mathrm{mg})$ were added to the suspension to result in carboxylic acid groups activation, and then EpCAM aptamer $(20 \mu \mathrm{l}, 5 \mu \mathrm{M})$ was added to the suspension and stirred overnight at room temperature (Fig. 9). Finally, targeted Apt-PEG-Au-NPs@DOX were pelleted by centrifugation at $17,000 \mathrm{~g}$ for $15 \mathrm{~min}$ and washed three times with deionized water.

\section{Physical characterization}

The FTIR analysis of all samples was performed to confirm proper conjugation of the functional groups in each step. Morphology and size of the prepared NPs were evaluated by atomic force microscopy (AFM; BRUKER, USA), high-resolution transmission electron microscopy (HR-TEM; FEI, USA) with an accelerating voltage of $200 \mathrm{kV}$ and field emission scanning electron microscopy (FESEM; TESCAN MIRA, Czech Republic) equipped with an energy-dispersive $\mathrm{X}$-ray spectrometer operated at $30 \mathrm{kV}$. Elemental compositions of the nanocarriers ( $\mathrm{Si}$, $\mathrm{Fe}, \mathrm{N}, \mathrm{C}, \mathrm{O}$, and $\mathrm{Au}$ ) were evaluated by energy-dispersive $\mathrm{X}$-ray analysis (EDX; TESCAN MIRA, Czech Republic). The particle sizes and surface zeta potential values were measured by Zeta Compact Potential Analyzer. Specific surface areas, pore size distribution and pore volume of SPION@MSNs and Au-NPs@DOX were determined using the Brunauer-Emmett-Teller (BET) and BarrettJoyner-Halenda (BJH) methods (BEL, Japan). The magnetic behavior of the SPION@MSNs and PEG-Au-NPs@ DOX was assessed by using vibrating sample magnetometer (VSM; Lake Shore Cryotronics, Netherlands). The conjugation of EpCAM aptamer on the surface of PEGAu-NPs@DOX was further checked by electrophoresis on agarose gel (2\%) along with the DNA marker. The electrophoresis was carried out at $80 \mathrm{~V}$ for $40 \mathrm{~min}$ in TBE

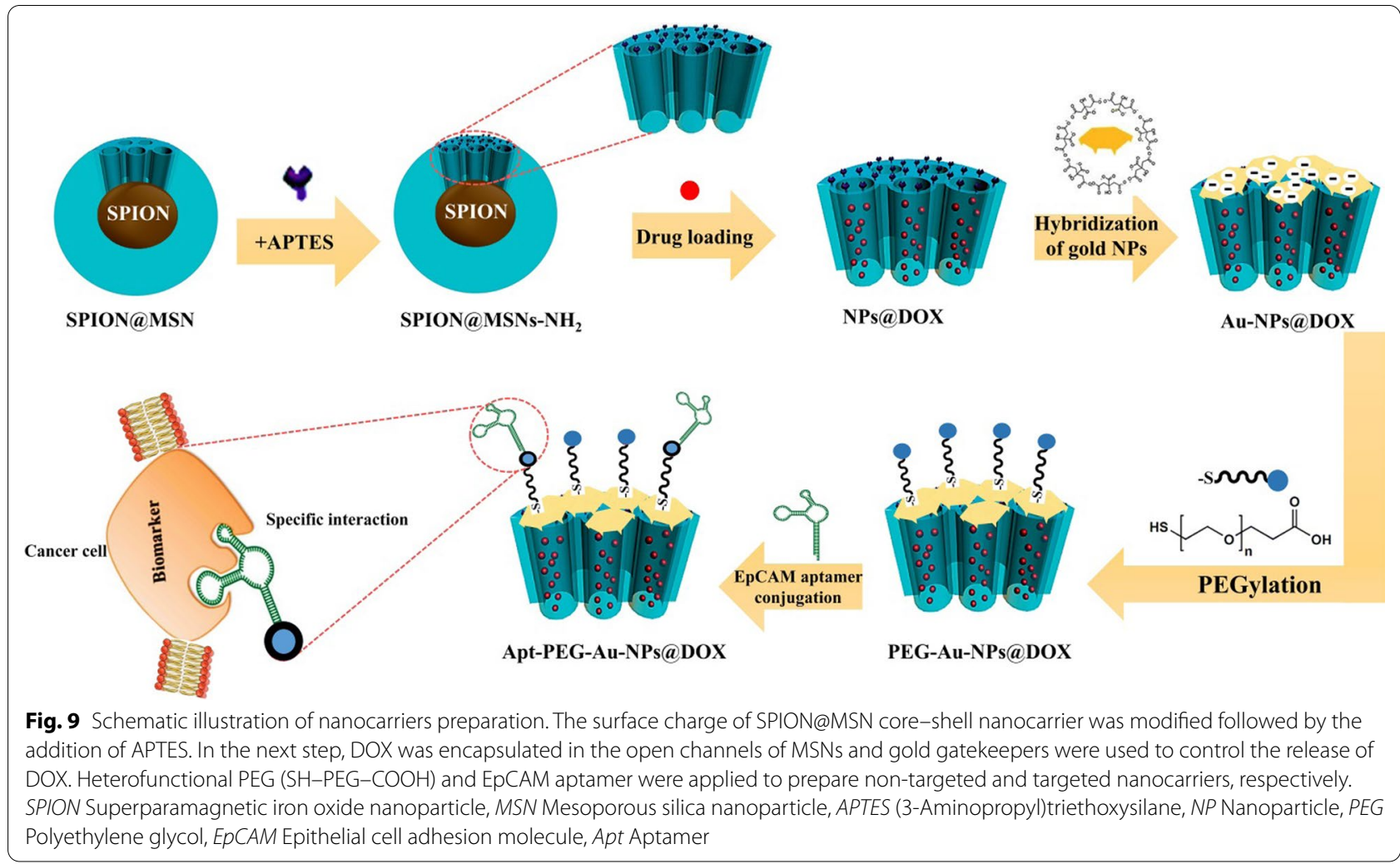


buffer. The gel was then stained with ethidium bromide $(0.5 \mathrm{mg} / \mathrm{ml})$ and imaged using gel documentation system (Major science, USA). Finally, thermogravimetric analysis (TGA; TA, USA) was performed at a heating rate of $20{ }^{\circ} \mathrm{C} / \mathrm{min}$ in air to evaluate the thermal profile of all NPs.

\section{In vitro drug release}

The pH-responsive drug release from Au-NPs@DOX was evaluated by dialysis membrane method. The mentioned NPs were dispersed in $3 \mathrm{ml}$ phosphate-buffered saline (PBS; $\mathrm{pH} 7.4$ ) and introduced into dialysis bags (cutoff $=1000 \mathrm{Da}$ ). Then, the sealed membrane was immersed in $30 \mathrm{ml}$ of release medium (PBS; $\mathrm{pH}=7.4$ and citrate buffer; $\mathrm{pH}=5.4$ ) and incubated at $37{ }^{\circ} \mathrm{C}$ with shaking at $60 \mathrm{rpm}$ for $96 \mathrm{~h}$. In specific time points, release media $(3 \mathrm{ml})$ were collected and replaced with the same volume of fresh release media to keep a constant volume. Eventually, the concentration of released DOX was determined by UV/Vis spectroscopy at $480 \mathrm{~nm}$. All assessments were performed in triplicate.

\section{Hemolysis assay}

Hemolysis test was developed to determine the potential cell lysis capacity of the prepared nanocarriers. For this purpose, human blood sample was obtained from a healthy donor and centrifuged $\left(1500 \mathrm{~g}\right.$ for $10 \mathrm{~min}$ at $4{ }^{\circ} \mathrm{C}$ ) to collect red blood cells (RBCs). After diluting pellets with PBS (1:10), different concentrations of SPION@ MSNs and PEG-Au-NPs@DOX (12.5 to $200 \mu \mathrm{g} / \mathrm{ml})$ were added to diluted samples and incubated at $37{ }^{\circ} \mathrm{C}$ in agitation at $100 \mathrm{rpm}$ for 12 and $24 \mathrm{~h}$. The mixtures were then centrifuged ( $2500 \mathrm{~g}$ for $1 \mathrm{~min}$ ), and the hemoglobin released in the supernatant was analyzed by enzymelinked immunosorbent assay (ELISA; Awareness Technology, USA). To confirm the hemolysis assay, distilled water and PBS were used as positive and negative controls, respectively and hemolysis percentage was measured via the following equation: three replicates. After 24, 48 and $72 \mathrm{~h}$ of treatments, $20 \mu \mathrm{l}$ of MTT solution ( $5 \mathrm{mg} / \mathrm{ml}$ in PBS) was added to each well and incubated for $4 \mathrm{~h}$ at $37{ }^{\circ} \mathrm{C}$. Afterwards, the media were removed and $160 \mu \mathrm{l}$ dimethyl sulfoxide (DMSO) was added to each well to dissolve the purple crystals. Finally, the optical density (OD) was measured at $540 \mathrm{~nm}$ using an ELISA reader and cell viability was compared with untreated cells, which were considered as $100 \%$ cell viability.

\section{In vitro cellular uptake}

The cellular uptake of nanocarriers was investigated by both flow cytometry technique and fluorescence microscopy. For this purpose, HT-29 and CHO cells were seeded in 6-well plates at a density of $2 \times 10^{5}$ cells/well and incubated for $24 \mathrm{~h}$. Then, free DOX, PEG-Au-NPs@DOX and Apt-PEG-Au-NPs@DOX (final concentration of DOX was $5 \mu \mathrm{g} / \mathrm{ml}$ ) were added to different wells and incubated for $6 \mathrm{~h}$. Subsequently, the cells were trypsinized, centrifuged ( $400 \mathrm{~g}$ for $15 \mathrm{~min}$ ) and resuspended in $300 \mu \mathrm{l}$ cold PBS (1X). The fluorescence intensity of cells was determined by a flow cytometer (BD Accuri C6, USA) in FL2 channel and related data were analyzed using FlowJo 7.6 software. Moreover, cellular uptake of nanocarriers was also observed by fluorescence microscopy. For this aim, after treatment of both cell types with mentioned concentrations of nanocarriers for $6 \mathrm{~h}$, they were washed three times with PBS, fixed in $4 \%$ paraformaldehyde $\left(15 \mathrm{~min}\right.$ at $4{ }^{\circ} \mathrm{C}$ ), and stained with DAPI for $10 \mathrm{~min}$ in the dark. After washing with PBS for three times, the cells were visualized under a fluorescent microscope (Olympus BX51, Japan).

\section{Studying cell death mechanism}

To evaluate the mechanism of cell death induced by prepared nanoparticles, HT-29 and CHO cells were seeded with a density of $2 \times 10^{5}$ cells/well in 6 -well plates for

$$
\text { Hemolysis } \%=\frac{\text { absorbance of NPs }- \text { absorbance of negative control }}{\text { absorbance of positive control }- \text { absorbance of negative control }} \times 100
$$

\section{In vitro cytotoxicity study}

The cytotoxicity of prepared nanocarriers was assessed on HT-29 and CHO cells as EpCAM positive and negative cell lines, respectively, using MTT assay according to the Mosmann method with some modifications [86]. Cells were cultured at seeding density of $8 \times 10^{3}$ cells/well in 96-well plates. The next day, the cell culture media were replaced and cell lines were treated with different concentration of free DOX, PEG-AuNPs@DOX and Apt-PEG-Au-NPs@DOX (100 $\mu \mathrm{g} / \mathrm{ml}$ to $1.56 \mu \mathrm{g} / \mathrm{ml}$; equivalent concentration of $\mathrm{DOX}$ ) in
$24 \mathrm{~h}$. Cells were then treated with free DOX, PEG-AuNPs@DOX and Apt-PEG-Au-NPs@DOX containing the equivalent amount of $5 \mu \mathrm{g} / \mathrm{ml}$ DOX for $48 \mathrm{~h}$. Afterwards, cells were collected and stained with Annexin V-FITC kit with PI according to the manufacturer's protocol. Finally, cells were subjected to flow cytometry to evaluate the mechanism of cell death induced by nanocarriers and the data were analyzed by FlowJo 7.6 software. 


\section{In vivo studies}

\section{Evaluation of anti-tumor efficacy}

The animal experiments were carried out following the guidelines approved by Animal Ethics Committee of Ferdowsi University of Mashhad (IR.UM.REC.1400.032). Immunosuppression of female C57BL/6 mice (4-6 weeks old) was performed as described previously [87]. $8 \times 10^{6}$ HT-29 cells (suspended in 1:1; FBS: Matrigel) were subcutaneously injected at the back of the immunocompromised mice. When tumors reached approximately 100-150 $\mathrm{mm}^{3}$, mice were randomized into four different experimental groups ( $\mathrm{n}=5$ per group) and intravenously treated with (1) PBS as control, (2) free DOX (1 mg/ $\mathrm{kg})$, (3) PEG-Au-NPs@DOX (1 mg/kg of DOX in $100 \mu \mathrm{l}$ NPs) and (4) Apt-PEG-Au-NPs@DOX (1 mg/kg of DOX in $100 \mu \mathrm{l} \mathrm{NPs}$ ) via the tail vein at days $1,3,6$ and 9. The growth of tumors was measured using a digital caliper (Mitutoyo, Japan) every other day.

\section{Evaluation of biosafety and biodistribution}

In order to assess the possible side effects, the body weights were monitored every other day for up to 15 days. The mice were then sacrificed and the major organs including liver, kidney, spleen, heart, lung, and tumor were collected for histological analysis with hematoxylin and eosin (H\&E) staining. Moreover, to investigate the distribution of nanocarriers, $100 \mu \mathrm{l}$ of free DOX, PEG-Au-NPs@DOX and Apt-PEG-Au-NPs@ DOX were injected at a concentration of $1 \mathrm{mg} / \mathrm{kg}$ DOX via the tail vein of immunocompromised mice bearing HT-29 tumors. The mice were then sacrificed at 12 and $24 \mathrm{~h}$ after injection, and the main mentioned organs were isolated for analysis by an in vivo imaging system (IVIS; KODAK, USA).

\section{Magnetic resonance imaging (MRI)}

MRI was conducted to evaluate the intratumoral accumulation of non-targeted and targeted nanocarriers [88]. When the tumor reached $200-300 \mathrm{~mm}^{3}$, the mice were tail-vein injected with PBS (as a control group), PEG-Au-NPs@DOX and Apt-PEG-Au-NPs@DOX. The T2-weighted coronal and axial images of the tumor were performed under a $1.5 \mathrm{~T}$ MRI scanner (MAGNETOM symphony; SIEMENS, Germany) with following parameters: protocol=turbo spin echo (TSE); repetition time $(\mathrm{TR})=5000 \mathrm{~ms}$; echo time $(\mathrm{TE})=91 \mathrm{~ms}$; resolution $=384 \times 384$ pixel and slice thickness $=3 \mathrm{~mm}$. Signal intensity measurements were conducted by DICOM viewer software (Medixant. RadiAnt DICOM Viewer [Software], Version 2020.2. Jul 19, 2020. URL: https://www.radiantviewer.com).

\section{Statistical analysis}

All the data were analyzed by one-way analysis of variance (ANOVA) or student's $t$-test with Tukey's multiple comparisons test using GraphPad Prism 6.0 (CA, USA). The level of significance for all statistical analysis was considered at 0.05 .

\section{Abbreviations}

5-FU: 5-Fluorouracil; APTES: (3-Aminopropyl)triethoxysilane; BET: BrunauerEmmett-Teller; CHO: Chinese hamster ovary; CTAB: N-Cetyltrimethylammonium bromide; DAPI: 4',6-Diamidino-2-phenylindole; DDS: Drug delivery system; DLS: Dynamic light scattering; DOX: Doxorubicin; EDC: 1-Ethyl-3-(3dimethylaminopropyl) carbodiimide hydrochloride; EpCAM: Epithelial cell adhesion molecule; EPR: Enhanced permeability and retention; FBS: Fetal bovine serum; FTIR: Fourier-transform infrared; g: Gravity; HA: Hyaluronic acid; HR-TEM: High resolution-transmission electron microscopy; MRI: Magnetic resonance imaging; MSN: Mesoporous silica nanoparticle; MTT: 3-(4,5-Dimethylthiazol-2-yl)-2, 5-diphenyltetrazolium bromide; NP: Nanoparticle; NHS: N-Hydroxysuccinimide; PEG: Polyethylene glycol; PI: Propidium iodide; RBC: Red blood cell; RPMI: Roswell Park Memorial Institute; SEM: Scanning electron microscopy; SPION: Superparamagnetic iron oxide; TEOS: Tetraethyl orthosilicate; TEM: Transmission electron microscopy; TGA: Thermal gravimetric analysis; TME: Tumor microenvironment; VSM: Vibration sample magnetometer.

\section{Supplementary Information}

The online version contains supplementary material available at https://doi. org/10.1186/s12951-021-01056-3.

Additional file 1: Figure S1. Fourier-transform infrared (FTIR) spectra of nanocarriers in each step of the catalyst fabrication. Figure S2. Energy-dispersive X-ray (EDX) mapping of (A) SPION@MSNs, (B) SPION@ MSNs-NH ${ }_{2}$, (C) Au-NPs@DOX and (D) PEG-Au-NPs@DOX. Figure S3. Gold NPs were synthesized and characterized by (A) TEM (scale bar is $32 \mathrm{~nm}$ ), (B) FTIR spectra and (C) UV/vis spectrophotometry. (D) The DLS results showed that gold NPs were around $7.92 \mathrm{~nm}$ and (E) zeta potential was around $-17.66 \mathrm{mV}$. Table S1. Signal intensity of non-targeted and targeted nanocarriers after 12 and $24 \mathrm{~h}$ post injection as revealed by MRI.

\section{Acknowledgements}

The authors would like to thank Mrs. Aseel Kamil Mohammed Al-Mosawi, Miss Elaheh Valizadeh-Kakhki, Miss Hasheminejad, Mr. Malaekeh, Mr. Azadeh, Dr. Noroozpour and Dr. Haniyeh Shaterzade for their excellent support and technical help.

\section{Authors' contributions}

SI: Conducted the methodology and inferences, carried out the statistical analyses, and wrote the manuscript. ARB: Advisor, had financial support, and proofread the manuscript. SN: Advisor, proofread the manuscript and carried out the MRI assessment. ASS: Supervisor, conceived the original idea and designed the study, had financial support, analyzed the results, and wrote the manuscript. MMM: Supervisor, conceived the original idea and designed the study, had financial support, analyzed the results, and wrote the manuscript. All authors read and approved the final manuscript.

\section{Funding}

This work was supported by Ferdowsi University of Mashhad, grant number: 3.51537 .

\section{Declarations}

Ethics approval and consent to participate

The animal experiments were carried out following the guidelines approved by Animal Ethics Committee of Ferdowsi University of Mashhad (IR. UM.REC.1400.032) 


\section{Consent for publication}

Not applicable.

\section{Competing interests}

The authors declare that there is no conflict of interest.

\section{Author details}

'Department of Biology, Faculty of Science, Ferdowsi University of Mashhad, Mashhad, Iran. ${ }^{2}$ Industrial Biotechnology Research Group, Institute of Biotechnology, Ferdowsi University of Mashhad, Mashhad, Iran. ${ }^{3}$ Department of Radiology, Faculty of Medicine, Mashhad University of Medical Sciences, Mashhad, Iran. ${ }^{4}$ Department of Chemistry, Faculty of Science, Ferdowsi University of Mashhad, Mashhad, Iran. ${ }^{5}$ Novel Diagnostics and Therapeutics Research Group, Institute of Biotechnology, Ferdowsi University of Mashhad, Mashhad, Iran

\section{Received: 16 August 2021 Accepted: 21 September 2021} Published online: 12 October 2021

\section{References}

1. Sung H, Ferlay J, Siegel RL, Laversanne M, Soerjomataram I, Jemal A, et al. Global cancer statistics 2020: GLOBOCAN estimates of incidence and mortality worldwide for 36 cancers in 185 countries. CA Cancer J Clin. 2021;71(3):209-49.

2. Srinivasan M, Rajabi M, Mousa SA. Multifunctional nanomaterials and their applications in drug delivery and cancer therapy. Nanomaterials. 2015;5(4):1690-703.

3. Janib SM, Moses AS, MacKay JA. Imaging and drug delivery using theranostic nanoparticles. Adv Drug Deliv Rev. 2010;62(11):1052-63.

4. Zhang W, Kan Q, Chen L, Xie L, Cui M, Xi Z, et al. Preparation and application of mesoporous core-shell nanosilica using leucine derivative as template in effective drug delivery. Chin Chem Lett. 2020;31(5):1165-7.

5. Florek J, Caillard R, Kleitz F. Evaluation of mesoporous silica nanoparticles for oral drug delivery-current status and perspective of MSNs drug carriers. Nanoscale. 2017;9(40):15252-77.

6. Liu Q, Zhang J, Sun W, Xie QR, Xia W, Gu H. Delivering hydrophilic and hydrophobic chemotherapeutics simultaneously by magnetic mesoporous silica nanoparticles to inhibit cancer cells. Int J Nanomed. 2012;7:999-1013.

7. Srivastava P, Hira SK, Paladhi A, Singh R, Gupta U, Srivastava DN, et al. Studies on interaction potency model based on drug synergy and therapeutic potential of triple stimuli-responsive delivery of doxorubicin and 5-fluoro-2-deoxyuridine against lymphoma using disulfidebridged cysteine over mesoporous silica nanoparticles. J Mater Chem B. 2020;8(7):1411-21.

8. Kong M, Tang J, Qiao Q, Wu T, Qi Y, Tan S, et al. Biodegradable hollow mesoporous silica nanoparticles for regulating tumor microenvironment and enhancing antitumor efficiency. Theranostics. 2017;7(13):3276-92.

9. Asefa T, Tao Z. Biocompatibility of mesoporous silica nanoparticles. Chem Res Toxicol. 2012;25(11):2265-84.

10. Bhaisare ML, Abdelhamid HN, Wu B-S, Wu H-F. Rapid and direct MALDIMS identification of pathogenic bacteria from blood using ionic liquidmodified magnetic nanoparticles (Fe 304 @ SiO 2). J Mater Chem B. 2014;2(29):4671-83

11. Abdelhamid HN, Wu H-F. Multifunctional graphene magnetic nanosheet decorated with chitosan for highly sensitive detection of pathogenic bacteria. J Mater Chem B. 2013;1(32):3950-61.

12. Wen J, Yang K, Liu F, Li H, Xu Y, Sun S. Diverse gatekeepers for mesoporous silica nanoparticle based drug delivery systems. Chem Soc Rev. 2017;46(19):6024-45

13. Song Y, Li Y, Xu Q, Liu Z. Mesoporous silica nanoparticles for stimuliresponsive controlled drug delivery: advances, challenges, and outlook. Int J Nanomed. 2017;12:87.

14. Liu R, Zhang Y, Zhao X, Agarwal A, Mueller LJ, Feng P. pH-responsive nanogated ensemble based on gold-capped mesoporous silica through an acid-labile acetal linker. J Am Chem Soc. 2010;132(5):1500-1.

15. Monem AS, Elbialy N, Mohamed N. Mesoporous silica coated gold nanorods loaded doxorubicin for combined chemo-photothermal therapy. Int J Pharm. 2014;470(1-2):1-7.
16. Babaei M, Abnous K, Taghdisi SM, Amel Farzad S, Peivandi MT, Ramezani $M$, et al. Synthesis of theranostic epithelial cell adhesion molecule targeted mesoporous silica nanoparticle with gold gatekeeper for hepatocellular carcinoma. Nanomedicine. 2017;12(11):1261-79.

17. Knop K, Hoogenboom R, Fischer D, Schubert US. Poly (ethylene glycol) in drug delivery: pros and cons as well as potential alternatives. Angew Chem Int Ed. 2010;49(36):6288-308.

18. Suk JS, Xu Q, Kim N, Hanes J, Ensign LM. PEGylation as a strategy for improving nanoparticle-based drug and gene delivery. Adv Drug Deliv Rev. 2016;99:28-51.

19. Alconcel SN, Baas AS, Maynard HD. FDA-approved poly (ethylene glycol)protein conjugate drugs. Polym Chem. 2011;2(7):1442-8.

20. Iranpour S, Bahrami AR, Saljooghi AS, Matin MM. Application of smart nanoparticles as a potential platform for effective colorectal cancer therapy. Coord Chem Rev. 2021;442:213949.

21. Matsumura Y, Maeda $\mathrm{H}$. A new concept for macromolecular therapeutics in cancer chemotherapy: mechanism of tumoritropic accumulation of proteins and the antitumor agent smancs. Cancer Res. 1986;46(12 Part 1):6387-92

22. Kato Y, Seita T, Kuwabara T, Sugiyama Y. Kinetic analysis of receptor-mediated endocytosis (RME) of proteins and peptides: use of RME as a drug delivery system. J Control Release. 1996;39(2-3):191-200.

23. Rosenblum D, Joshi N, Tao W, Karp JM, Peer D. Progress and challenges towards targeted delivery of cancer therapeutics. Nat Commun. 2018;9(1):1-12.

24. Boogerd LS, van der Valk MJ, Boonstra MC, Prevoo HA, Hilling DE, van de Velde CJ, et al. Biomarker expression in rectal cancer tissue before and after neoadjuvant therapy. Onco Targets Ther. 2018;11:1655.

25. Xie X, Li F, Zhang H, Lu Y, Lian S, Lin H, et al. EpCAM aptamer-functionalized mesoporous silica nanoparticles for efficient colon cancer celltargeted drug delivery. Eur J Pharm Sci. 2016;83:28-35.

26. Li Y, Duo Y, Bao S, He L, Ling K, Luo J, et al. EpCAM aptamer-functionalized polydopamine-coated mesoporous silica nanoparticles loaded with DM1 for targeted therapy in colorectal cancer. Int J Nanomed. 2017;12:6239.

27. Gao Y, Xie X, Li F, Lu Y, Li T, Lian S, et al. A novel nanomissile targeting two biomarkers and accurately bombing CTCs with doxorubicin. Nanoscale. 2017:9(17):5624-40

28. Song Y, Zhu Z, An Y, Zhang W, Zhang H, Liu D, et al. Selection of DNA aptamers against epithelial cell adhesion molecule for cancer cell imaging and circulating tumor cell capture. Anal Chem. 2013;85(8):4141-9.

29. Dong L, Peng H, Wang S, Zhang Z, Li J, Ai F, et al. Thermally and magnetically dual-responsive mesoporous silica nanospheres: preparation, characterization, and properties for the controlled release of sophoridine. J Appl Polym Sci. 2014. https://doi.org/10.1002/app.40477.

30. Srivastava P, Hira SK, Sharma A, Kashif M, Srivastava P, Srivastava DN, et al. Telomerase responsive delivery of doxorubicin from mesoporous silica nanoparticles in multiple malignancies: therapeutic efficacies against experimental aggressive murine lymphoma. Bioconjug Chem. 2018;29(6):2107-19.

31. Dau TAN, Pham TKH, Cho SK, Nguyen TNU, Ta TKH, Van Tran TT. Surface functionalization of doxorubicin loaded MCM-41 mesoporous silica nanoparticles by 3-aminopropyltriethoxysilane for selective anticancer 9 effect on A549 and A549/DOX cells. J Electron Mater. 2021:50(5):2932-9.

32. Abdelhamid HN, Lin YC, Wu H-F. Magnetic nanoparticle modified chitosan for surface enhanced laser desorption/ionization mass spectrometry of surfactants. RSC Adv. 2017;7(66):41585-92.

33. Vivero-Escoto JL, Slowing II, Wu CW, Lin VSY. Photoinduced intracellular controlled release drug delivery in human cells by gold-capped mesoporous silica nanosphere. J Am Chem Soc. 2009;131(10):3462-3.

34. Hsiao PF, Peng S, Tang T-C, Lin S-Y, Tsai H-C. Enhancing the in vivo transdermal delivery of gold nanoparticles using poly (ethylene glycol) and its oleylamine conjugate. Int J Nanomed. 2016;11:1867.

35. Keleş E, Hazer B, Cömert FB. Synthesis of antibacterial amphiphilic elastomer based on polystyrene-block-polyisoprene-block-polystyrene via thiol-ene addition. Mater Sci Eng, C. 2013;33(3):1061-6.

36. Sun X, Wu Y, Gao W, Enjyoji K, Csizmadia E, Müller CE, et al. CD39/ENTPD1 expression by CD4+ Foxp3+ regulatory $T$ cells promotes hepatic metastatic tumor growth in mice. Gastroenterology. 2010;139(3):1030-40. 
37. Wang L, Yu K, Zhou B-B, Su Z-H, Gao S, Chu L-L, et al. The inhibitory effects of a new cobalt-based polyoxometalate on the growth of human cancer cells. Dalton Trans. 2014:43(16):6070-8.

38. Sun T, Cui W, Yan M, Qin G, Guo W, Gu H, et al. Target delivery of a novel antitumor organoplatinum (IV)-substituted polyoxometalate complex for safer and more effective colorectal cancer therapy in vivo. Adv Mater 2016;28(34):7397-404

39. Ji YM, Zhao M, Han PP, Fang Y, Han QX, Li MX. Cobalt (II) compound derived from Strandberg-type polyoxometalate clusters: synthesis, crystal structures and biological activities. Inorg Nano-Metal Chem. 2018:48(8):421-5.

40. Tahmasebi M, Mirzaei M, Matin MM, Iranpour S, Mague JT. Biological insights of a chiral hybrid-based $\gamma$-octamolybdate and proline. J Mol Struct. 2021;1247:131401.

41. Gabas IM, Stepien G, Moros M, Mitchell SG, Jesús M. In vitro cell cytotoxicity profile and morphological response to polyoxometalate-stabilised gold nanoparticles. New J Chem. 2016;40(2):1039-47.

42. Fu L, Gao H, Yan M, Li S, Li X, Dai Z, et al. Polyoxometalate-based organicinorganic hybrids as antitumor drugs. Small. 2015;11(24):2938-45.

43. Bijelic A, Aureliano M, Rompel A. Polyoxometalates as potential nextgeneration metallodrugs in the combat against cancer. Angew Chem Int Ed. 2019;58(10):2980-99.

44. Ammam M. Polyoxometalates: formation, structures, principal properties, main deposition methods and application in sensing. J Mater Chem A. 2013;1(21):6291-312.

45. Vakili-Ghartavol R, Momtazi-Borojeni AA, Vakili-Ghartavol Z, Aiyelabegan $H T$, Jaafari MR, Rezayat SM, et al. Toxicity assessment of superparamagnetic iron oxide nanoparticles in different tissues. Artif Cells Nanomed Biotechnol. 2020:48(1):443-51.

46. Diab R, Canilho N, Pavel IA, Haffner FB, Girardon M, Pasc A. Silica-based systems for oral delivery of drugs, macromolecules and cells. Adv Coll Interface Sci. 2017;249:346-62.

47. Muthu MS, Leong DT, Mei L, Feng S-S. Nanotheranostics- application and further development of nanomedicine strategies for advanced theranostics. Theranostics. 2014:4(6):660-77.

48. Rasouli E, Basirun WJ, Rezayi M, Shameli K, Nourmohammadi E, Khandanlou R, et al. Ultrasmall superparamagnetic Fe3O4 nanoparticles: honey-based green and facile synthesis and in vitro viability assay. Int J Nanomed. 2018;13:6903.

49. He Q, Zhang Z, Gao F, Li Y, Shi J. In vivo biodistribution and urinary excretion of mesoporous silica nanoparticles: effects of particle size and PEGylation. Small. 2011;7(2):271-80.

50. Desai D, Prabhakar N, Mamaeva V, Karaman DŞ, Lähdeniemi IA, Sahlgren $C$, et al. Targeted modulation of cell differentiation in distinct regions of the gastrointestinal tract via oral administration of differently PEGPEI functionalized mesoporous silica nanoparticles. Int J Nanomed. 2016:11:299.

51. Wani A, Savithra GHL, Abyad A, Kanvinde S, Li J, Brock S, et al. Surface PEGylation of mesoporous silica nanorods (MSNR): effect on loading, release, and delivery of mitoxantrone in hypoxic cancer cells. Sci Rep. 2017:7(1):1-11.

52. Lowe G, Stike R, Pollack M, Bosley J, O'Brien P, Hake A, et al. Nursing blood specimen collection techniques and hemolysis rates in an emergency department: analysis of venipuncture versus intravenous catheter collection techniques. J Emerg Nurs. 2008;34(1):26-32.

53. Gerashchenko BI, Gun'ko VM, Gerashchenko II, Mironyuk IF, Leboda R, Hosoya H. Probing the silica surfaces by red blood cells. Cytometry J Int Soc Anal Cytol. 2002;49(2):56-61.

54. Murashov V, Harper M, Demchuk E. Impact of silanol surface density on the toxicity of silica aerosols measured by erythrocyte haemolysis. J Occup Environ Hyg. 2006;3(12):718-23.

55. Slowing II, Wu CW, Vivero-Escoto JL, Lin VSY. Mesoporous silica nanoparticles for reducing hemolytic activity towards mammalian red blood cells. Small. 2009;5(1):57-62.

56. Vázquez-Iglesias L, Barcia-Castro L, Rodríguez-Quiroga M, de la Cadena MP, Rodríguez-Berrocal J, Cordero OJ. Surface expression marker profile in colon cancer cell lines and sphere-derived cells suggests complexity in CD26+ cancer stem cells subsets. Biol Open. 2019;8(7):bio041673.

57. Amann M, Friedrich M, Lutterbuese P, Vieser E, Lorenczewski G, Petersen $L$, et al. Therapeutic window of an EpCAM/CD3-specific BiTE antibody in mice is determined by a subpopulation of EpCAM-expressing lymphocytes that is absent in humans. Cancer Immunol Immunother. 2009;58(1):95-109.

58. Mashreghi M, Zamani P, Moosavian SA, Jaafari MR. Anti-Epcam aptamer (Syl3c)-functionalized liposome for targeted delivery of doxorubicin: In vitro and in vivo antitumor studies in mice bearing C26 colon carcinoma. Nanoscale Res Lett. 2020;15:1-13.

59. Sakhtianchi R, Darvishi B, Mirzaie Z, Dorkoosh F, Shanehsazzadeh S, Dinarvand R. Pegylated magnetic mesoporous silica nanoparticles decorated with AS1411 Aptamer as a targeting delivery system for cytotoxic agents. Pharm Dev Technol. 2019;24(9):1063-75.

60. Siminzar P, Omidi Y, Golchin A, Aghanejad A, Barar J. Targeted delivery of doxorubicin by magnetic mesoporous silica nanoparticles armed with mucin-1 aptamer. J Drug Target. 2020;28(1):92-101.

61. Yu M, Jambhrunkar S, Thorn P, Chen J, Gu W, Yu C. Hyaluronic acid modified mesoporous silica nanoparticles for targeted drug delivery to CD44overexpressing cancer cells. Nanoscale. 2013;5(1):178-83.

62. Liu K, Wang ZQ, Wang SJ, Liu P, Qin YH, Ma Y, et al. Hyaluronic acid-tagged silica nanoparticles in colon cancer therapy: therapeutic efficacy evaluation. Int J Nanomed. 2015;10:6445.

63. Zhang M, Xu C, Wen L, Han MK, Xiao B, Zhou J, et al. A hyaluronidaseresponsive nanoparticle-based drug delivery system for targeting colon cancer cells. Can Res. 2016;76(24):7208-18.

64. Li Y, Duo Y, Zhai P, He L, Zhong K, Zhang Y, et al. Dual targeting delivery of miR-328 by functionalized mesoporous silica nanoparticles for colorectal cancer therapy. Nanomedicine. 2018;13(14):1-20.

65. Maetzel D, Denzel S, Mack B, Canis M, Went P, Benk M, et al. Nuclear signalling by tumour-associated antigen EpCAM. Nat Cell Biol. 2009;11(2):162-71.

66. Wang $M-H$, Sun $R$, Zhou X-M, Zhang M-Y, Lu J-B, Yang Y, et al. Epithelial cell adhesion molecule overexpression regulates epithelial-mesenchymal transition, stemness and metastasis of nasopharyngeal carcinoma cells via the PTEN/AKT/mTOR pathway. Cell Death Dis. 2018;9(1):1-16.

67. Zhang Z, Wang H, Tan T, Li J, Wang Z, Li Y. Rational design of nanoparticles with deep tumor penetration for effective treatment of tumor metastasis. Adv Func Mater. 2018;28(40):1801840.

68. Cheng Z, Ma P, Hou Z, Wang W, Dai Y, Zhai X, et al. YVO 4: Eu 3+ functionalized porous silica submicrospheres as delivery carriers of doxorubicin. Dalton Trans. 2012;41(5):1481-9.

69. Singh NS, Kulkarni H, Pradhan L, Bahadur D. A multifunctional biphasic suspension of mesoporous silica encapsulated with YVO4: Eu3+ and Fe3O4 nanoparticles: synergistic effect towards cancer therapy and imaging. Nanotechnology. 2013;24(6):065101.

70. Sahoo B, Devi KSP, Dutta S, Maiti TK, Pramanik P, Dhara D. Biocompatible mesoporous silica-coated superparamagnetic manganese ferrite nanoparticles for targeted drug delivery and MR imaging applications. J Colloid Interface Sci. 2014;431:31-41.

71. Che E, Wan L, Zhang Y, Zhao Q, Han X, Li J, et al. Development of phosphonate-terminated magnetic mesoporous silica nanoparticles for $\mathrm{pH}$-controlled release of doxorubicin and improved tumor accumulation. Asian J Pharm Sci. 2014;9(6):317-23.

72. Tao C, Zhu Y. Magnetic mesoporous silica nanoparticles for potential delivery of chemotherapeutic drugs and hyperthermia. Dalton Trans. 2014;43(41):15482-90.

73. Hurley KR, Ring HL, Etheridge M, Zhang J, Gao Z, Shao Q, et al. Predictable heating and positive MRI contrast from a mesoporous silica-coated iron oxide nanoparticle. Mol Pharm. 2016;13(7):2172-83.

74. Azhdarzadeh M, Atyabi F, Saei AA, Varnamkhasti BS, Omidi Y, Fateh M, et al. Theranostic MUC-1 aptamer targeted gold coated superparamagnetic iron oxide nanoparticles for magnetic resonance imaging and photothermal therapy of colon cancer. Colloids Surf, B. 2016;143:224-32.

75. Cheng B, He H, Huang T, Berr SS, He J, Fan D, et al. Gold nanosphere gated mesoporous silica nanoparticle responsive to near-infrared light and redox potential as a theranostic platform for cancer therapy. J Biomed Nanotechnol. 2016:12(3):435-49.

76. Yang R-M, Fu C-P, Fang J-Z, Xu X-D, Wei X-H, Tang W-J, et al. Hyaluronanmodified superparamagnetic iron oxide nanoparticles for bimodal breast cancer imaging and photothermal therapy. Int J Nanomed. 2017:12:197-206.

77. Luo X, Peng X, Hou J, Wu S, Shen J, Wang L. Folic acid-functionalized polyethylenimine superparamagnetic iron oxide nanoparticles as theranostic 
agents for magnetic resonance imaging and PD-L1 siRNA delivery for gastric cancer. Int J Nanomed. 2017;12:5331-43.

78. Ansari L, Jaafari MR, Bastami TR, Malaekeh-Nikouei B. Improved anticancer efficacy of epirubicin by magnetic mesoporous silica nanoparticles: in vitro and in vivo studies. Artif Cells Nanomed Biotechnol. 2018;46(sup2):594-606.

79. Licciardi M, Scialabba C, Puleio R, Cassata G, Cicero L, Cavallaro G, et al. Smart copolymer coated SPIONs for colon cancer chemotherapy. Int J Pharm. 2019;556:57-67.

80. Wu Z-Y, Lee C-C, Lin H-M. Hyaluronidase-responsive mesoporous silica nanoparticles with dual-imaging and dual-target function. Cancers. 2019;11(5):697-710.

81. Niu S, Zhang X, Williams GR, Wu J, Gao F, Fu Z, et al. Hollow mesoporous silica nanoparticles gated by chitosan-copper sulfide composites as theranostic agents for the treatment of breast cancer. Acta Biomater. 2021;126:408-20.

82. Yang P, Quan Z, Hou Z, Li C, Kang X, Cheng Z, et al. A magnetic, luminescent and mesoporous core-shell structured composite material as drug carrier. Biomaterials. 2009;30(27):4786-95.

83. She $\mathrm{X}$, Chen L, Velleman L, Li C, Zhu H, He C, et al. Fabrication of high specificity hollow mesoporous silica nanoparticles assisted by Eudragit for targeted drug delivery. J Colloid Interface Sci. 2015;445:151-60.
84. Pignatello R, Amico D, Chiechio S, Spadaro C, Puglisi G, Giunchedi P. Preparation and analgesic activity of eudragit RS100 ${ }^{\circledR}$ microparticles containing diflunisal. Drug Deliv. 2001;8(1):35-45.

85. Frens $\mathrm{G}$. Controlled nucleation for the regulation of the particle size in monodisperse gold suspensions. Nat Phys Sci. 1973;241(105):20-2.

86. Mosmann T. Rapid colorimetric assay for cellular growth and survival: application to proliferation and cytotoxicity assays. J Immunol Methods. 1983;65(1-2):55-63.

87. Iranpour S, Al-Mosawi AKM, Bahrami AR, Sadeghian H, Matin MM. Investigating the effects of two novel 4-MMPB analogs as potent lipoxygenase inhibitors for prostate cancer treatment. J Biol Res Thessaloniki. 2021;28(1):10

88. Li Y, Xin J, Sun Y, Han T, Zhang H, An F. Magnetic resonance imagingguided and targeted theranostics of colorectal cancer. Cancer Biol Med. 2020;17(2):307-27.

\section{Publisher's Note}

Springer Nature remains neutral with regard to jurisdictional claims in published maps and institutional affiliations.
Ready to submit your research? Choose BMC and benefit from:

- fast, convenient online submission

- thorough peer review by experienced researchers in your field

- rapid publication on acceptance

- support for research data, including large and complex data types

- gold Open Access which fosters wider collaboration and increased citations

- maximum visibility for your research: over $100 \mathrm{M}$ website views per year

At BMC, research is always in progress.

Learn more biomedcentral.com/submissions 